\title{
Applications of Vitrinite Anisotropy in the Tectonics: A Case Study of Huaibei Coalfield, Southern North China
}

\author{
Yudong Wu, ${ }^{1,2}$ Quanlin Hou, ${ }^{2}$ Yiwen Ju, ${ }^{2}$ Daiyong Cao, ${ }^{3}$ Junjia Fan, ${ }^{4}$ and Wei Wei ${ }^{2}$ \\ ${ }^{1}$ MLR Key Laboratory of Metallogeny and Mineral Assessment, Institute of Mineral Resources, CAGS, Beijing 100037, China \\ ${ }^{2}$ Key Lab of Computational Geodynamics of Chinese Academy of Sciences and College of Earth Science, \\ Graduate University of the Chinese Academy of Sciences, Beijing 100049, China \\ ${ }^{3}$ Key Laboratory of Coal Resources, China University of Mining and Technology, Beijing 100083, China \\ ${ }^{4}$ Key laboratory of Basin Structure and Petroleum Accumulation, CNPC and PetroChina Research Institute \\ of Petroleum Exploration and Development, Beijing 100083, China
}

Correspondence should be addressed to Quanlin Hou, quhou@gucas.ac.cn

Received 28 February 2012; Accepted 6 April 2012

Academic Editor: Hongyuan Zhang

Copyright ( 2012 Yudong Wu et al. This is an open access article distributed under the Creative Commons Attribution License, which permits unrestricted use, distribution, and reproduction in any medium, provided the original work is properly cited.

\begin{abstract}
29 oriented and 10 nonoriented coal samples are collected in the study from three different regions of the Huaibei coalfield, eastern China, and their vitrinite reflectance indicating surface (RIS) parameters are systematically calculated and analyzed. Using the available methods, Kilby's transformations and RIS triaxial orientations are obtained. The magnitudes and orientations of the RIS axes of the three regions were respectively projected on the horizontal planes and vertical sections. The results show that the samples in high deformed region have significant anisotropy magnitudes (higher $B_{\mathrm{w}} / R_{\max }$ and $R_{\mathrm{am}}$ values) with a biaxial negative style, whereas the samples in the slightly deformed area have unimpressive anisotropy magnitudes with a biaxial negative style. Thermal metamorphism superposed might enhance the complication and variation of RIS style. RIS projection analysis deduced that the RIS orientation is mainly controlled by regional tectonic stress, and likely influenced by deformation mechanisms of coal.
\end{abstract}

\section{Introduction}

During the coalification, tectonic-thermal events could influence the vitrinite reflectance of coal $[1,2]$. Effects of temperature and stress on modifying vitrinite reflectance anisotropy (VRA) were proved by high temperature-pressure experiments on bituminous anthracite [3-13]. Patterns of VRA $[14,15]$ in coal are usually represented by a threedimensional graphical form resembling an ellipsoid and termed as RIS (reflectance indicating surface).

The investigation of the RIS for vitrinite in coals is performed by means of sections cut from oriented samples, and the magnitudes and orientations of the ellipsoid parameters are obtained by calculating the data measured from three mutually perpendicular surfaces. This method has been reported [14] and verified by high temperature-pressure experiments [16] and tectonic stress field analysis [11, 15, 17-20]. The anisotropy of RIS in this method is quantified by a function of rank [15], including in terms of bireflectance ratio [21], anisotropy ratio [17] and bireflectance [22].

The RIS styles may also be obtained by nonoriented sections from crushed coal samples. The method requires measurement of the maximum and minimum apparent reflectance from a series of randomly oriented vitrinite particles, and the magnitudes of RIS principal reflectance axes were estimated by using the reflectance crossplots $[23,24]$. A series of parameters named as Kilby's transformations in the method are proposed more effectively to estimate the anisotropy magnitude and shape of RIS ellipsoid, including RIS style $\left(R_{\mathrm{st}}\right)$, anisotropy magnitude $\left(R_{\mathrm{am}}\right)$, and reflectance of equivalent volume isotropic RIS $\left(R_{\mathrm{ev}}\right)$. Compared with Levine's method, basing on the application of vitrinite maximum reflectance versus vitrinite random reflectance [25], less time consuming is found during Kilby's data processing $[13,23,26-30]$. In the nonoriented sections, 
however, the orientations of three principal reflectance axes are missing.

Previous works suggested that the anisotropic strains developed by lithostatic pressure, especially by tectonic strains, including oriented pressures and shears. High rank coals and anthracites show evidence of the presence of biaxial negative materials $[15,19,23,31,32]$. As the result of tectonic dislocations, in many cases associated with fractures in the plane normal to the coal bedding, it is possible to find microtextures responsible for the biaxial positive character $[29,30]$. It is found that minimum reflectance develops incrementally parallel to the direction of maximum compressive stress $\left(\sigma_{1}\right)$ during coalification, and maximum reflectance develops incrementally parallel to the direction of minimum compressive stress $\left(\sigma_{3}\right)[1,14]$. These viewpoints are verified by simple shear experiments in high temperature-pressure environment $[28,33,34]$. On this basis, the RIS may approximate to finite strain ellipsoid [35], and the orientations and magnitudes of RIS principal reflectance axes may correspondingly have further usages in the tectonic stress field analysis.

The Huaibei Coalfield in Anhui Province of China has abundant coal resources. Thermal model research showed that the coal experienced low temperature $\left(<230^{\circ} \mathrm{C}\right)$ after being buried during the coalification process [36] and, therefore, thermal function was limited in the coalification history. Although the coalification process was influenced by other geological agencies such as tectonic stress, the RIS parameters may provide semiquantitative information about the magnitudes and orientations of tectonic deformation.

In this paper, 29 oriented coal samples from the working face of the underground mines and 10 nonoriented coal samples from the core drilling were collected. In order to estimate the magnitudes and orientations of the three principal reflectance axes, the RIS was built on the oriented coal sample blocks. The orientation of RIS was obtained by calculating the data measured from three mutually perpendicular surfaces. Meanwhile, the anisotropy magnitude and shape were analyzed with the parameters such as bireflectance ratio, Flinn's diagram, and Kilby's transformations. The effects of tectonic stress and thermal evolution on coal are therefore expected to be evaluated.

\section{Geology of the Study Area}

The Huaibei Coalfield in the southeast area of North China Craton was influenced by the Tancheng-Lujiang sinistral strike-slip fault in Mesozoic [39-42] and a related arcuate thrust system [37]. Many researchers believed that the arcuate thrust system was a west-thrust imbricate fan with the arc-top near to Huaibei City [37, 43]. A syncline formed in the margin of the thrust system had a certain influence on the burial depth of coal seams and the level of coal rank [44]. Coal-bearing strata mainly occur in Permo-Carboniferous age.

The Huaibei Coalfield is divided into three regions representing different stress-thermal environments. Vitrinite reflectance of coal samples collected from these regions was measured and sampling locations are shown in Figure 1(a).

(1) Region A, including the coal mines of Taoyuan (label 3), Qinan (label 4), Qidong (label 5), and Xutuan (label 9). The strata were likely influenced less by magmatism and tectonic agency and more by burial metamorphism.

(2) Region B, including the coal mines of Haizi (label 6), Linhuan (label 7), Tongting (label 8) and Baishan (label 10). Both Mesozoic deformation and magmatism affected deeply the strata and likely impacted on the samples collected in the region.

(3) Region C, including the coal mines of Luling (label 1), Zhuxianzhuang (label 2), Shitai (label 11) and Yangzhuang (label 12). The strata in the region strongly deformed, and samples are probably highly influenced by effects of tectonic deformation and thermal-shearing.

(4) The lithostratigraphic sequence of the study area is shown in Figure $1(\mathrm{~b})$. The major coal seams occur in the lower Permian system $\left(P_{1}\right)$ and minor coal seams locally occur in the upper Permian System $\left(P_{2}\right)$. Southward marine regression during early Permian time led to deposition in an islandlagoon environment and followed by terrestrial deltaplain deposits that contained extensive and minable coal seams [44]. The deltaic environment became unstable in early Late Permian, and coal seams became thinned, discontinuous and unminable. The alluvial deposits in Late Permian marked the end of coal accumulation in the Huaibei coalfield [44]. All the oriented samples collected from the working face in coal seams of 3rd, 7th, 8th and 10th and the nonoriented samples collected from the well-drills belonging to the Permian strata.

\section{Experimental Section}

Coal macerals of samples were determined by spot checks before the reflectance measurement, and the reflectance was measured by means of the method described in GB/T 8899-1998 (equated with ISO7404/3 standard). At least 500 points for each sample were measured on the same polished specimen. The contents of vitrinite, inertinite, liptinite, and mineral matter were obtained and are shown in Table 1. Coal lithotype in the Huaibei coalfield is dominated by clarain, with secondary durian and vitrain, and coal maceral is dominated by vitrinite (40.6 92.5\%), which is followed by inertinite and liptinite (Table 1).

3.1. Sample Preparation. The 29 oriented samples were prepared following the rules described in GB/T 16773-2008 (equated with ISO7404/2 standard) and cut into cubes with approximately $3-4 \mathrm{~cm}$ in dimensions (Figure 2 ). One pair of planes are paralleling to the horizontal plane and the other two mutually perpendicular pairs normal to the horizontal one. Each sample, therefore, has three pairs of mutually 

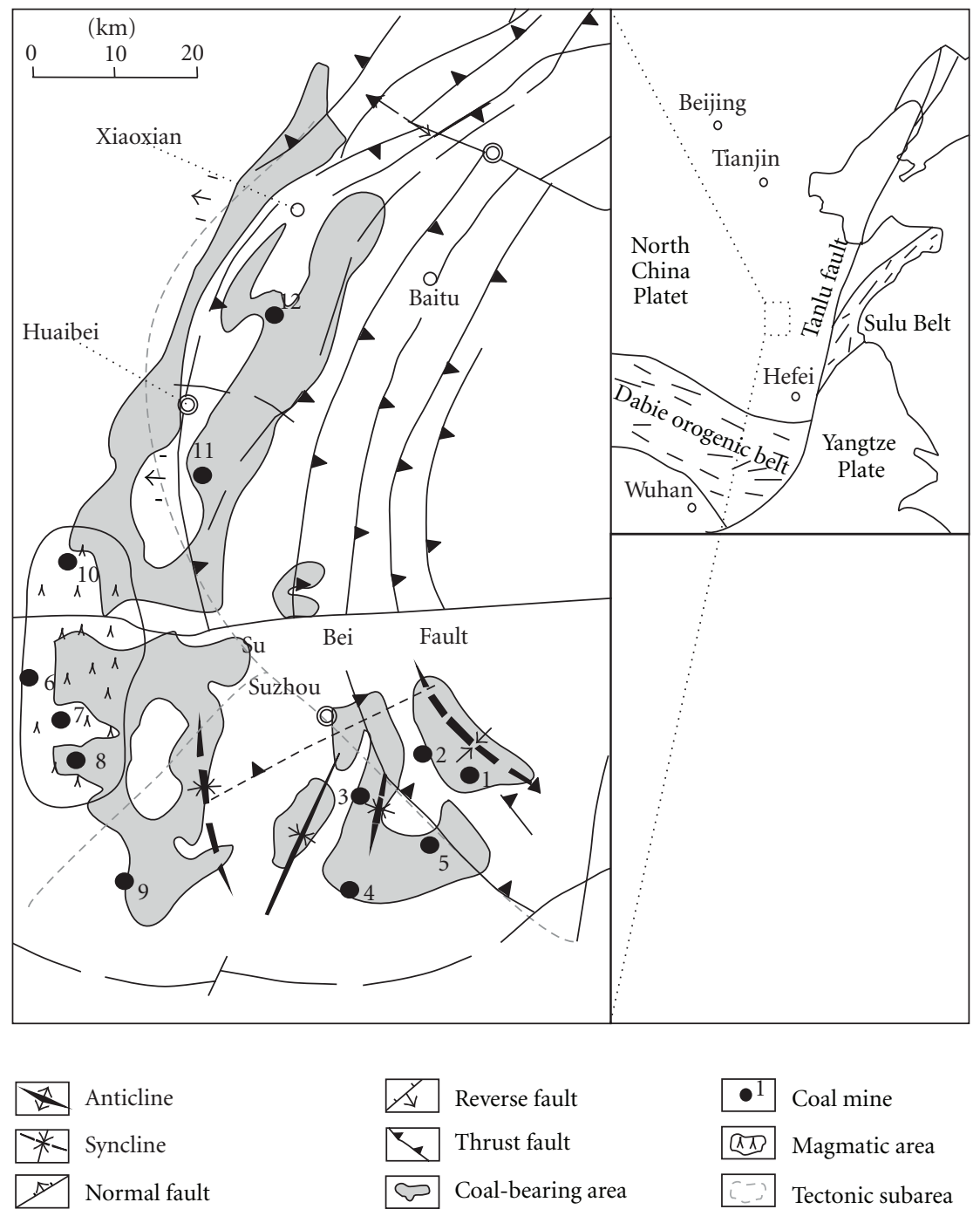

$\triangle 1$
$\square$ Reverse fault
$\infty \quad$ Coal-bearing area

(a)
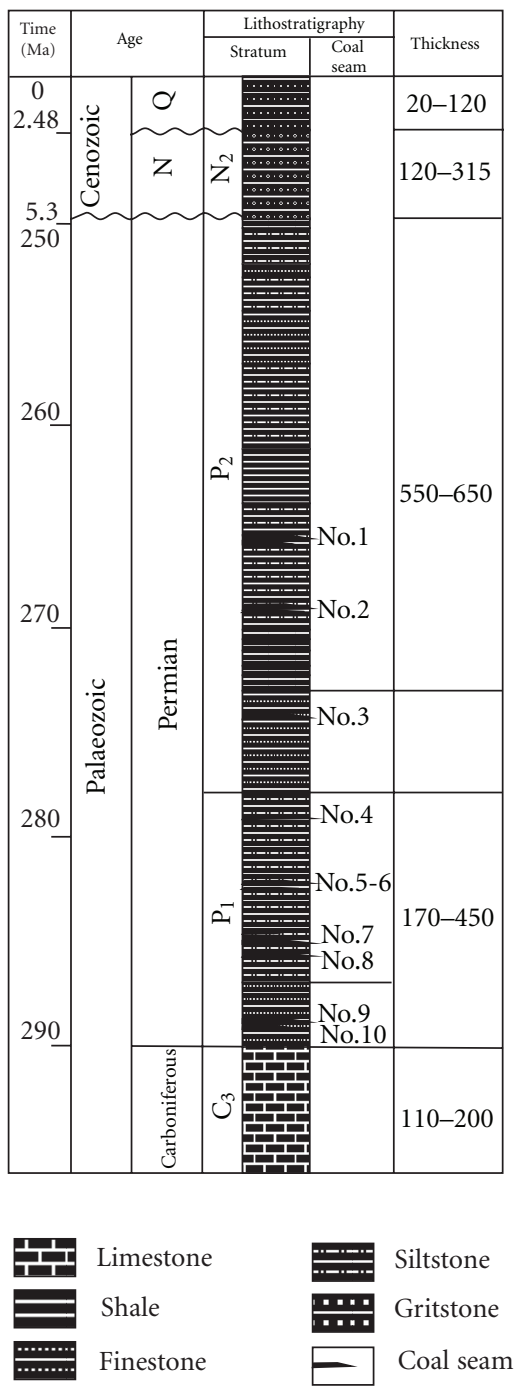

(b)

Figure 1: Simplified geologic map with late Paleozoic stratigraphic column of the Huaibei Coalfield. Coal mine label: (1) Luling mine, (2) Zhuxianzhuang mine, (3) Taoyuan mine, (4) Qinan mine, (5) Qidong mine, (6) Haizi mine, (7) Linhuan mine, (8) Tongting mine, (9) Xutuan mine, (10) Baishan mine, (11) Yangzhuang mine, (12) Shitai mine, The location is shown in the inset of Figure 1(a): Areas in gray where Upper Permian coal bearing strata are preserved in the Huaibei coalfield. Oriented coal samples were gathered from the Luling (LL), Taoyuan (TY), Haizi (HZ), Linhuan (LH), Xutuan (XT), Shitai (ST), and Yangzhuang (YZ) mines. The nonoriented coal samples were collected from bore holes in TY, XT, LH and Qidong (QD) coal mines. As shown in Figure 1(b), the Mesozoic and lower Cenozoic strata were suffered from erosion and missed. The Permian strata mainly consist of sandy mudstone and fine sandstone with 10 major coal seams (Nos. 1 10). Geological data are compiled based on $[37,38]$ the stratigraphic column is modified from China National Administration of coal Geology (1996).

perpendicular surfaces $\left(\mathrm{a} / \mathrm{a}^{\prime}, \mathrm{b} / \mathrm{b}^{\prime}\right.$, and $\mathrm{c} / \mathrm{c}^{\prime}$ as shown in Figure 2) under the process of polishing surface.

The 11 nonoriented samples were prepared by a modified procedure of GB/T 16773-2008 (equated with ISO 7404/02 standard). These samples were also used in our previous work for thermal simulation of maturation for coal [36].

3.2. Optical Microscopic Measurements. The measurements were performed for each oriented sample using an MPV-3
Combi (Leitz) microscope, reflected light, and oil immersion objectives. The maximum and minimum apparent reflectance $\left(R_{\max }\right.$ and $\left.R_{\min }\right)$ on each polished surface were measured in polarized light $(\lambda=546 \mu)$ and by rotating the microscope stage through $360^{\circ}$ and following the analytical method described in GB/T 6948-2008 (equated with ISO7404/5 standard). at least 20 points on each surface of each sample were measured to obtain the mean statistical values and azimuths of $R_{\max }$ and $R_{\min }$. 
TABLE 1: Maceral composition of coal samples studied.

\begin{tabular}{lcccc}
\hline Sample number & $V(\%)$ & $I(\%)$ & $E(\%)$ & $M M(\%)$ \\
\hline TYM03 & 40.6 & 22.5 & 36.7 & 0.2 \\
TY02 & 66.4 & 18.4 & 14.4 & 0.8 \\
XTM08 & 89.2 & 9.2 & 0.8 & 0.8 \\
LHM03 & 67.4 & 31.7 & $x$ & 0.9 \\
LHM02 & 81.9 & 17.4 & $x$ & 0.7 \\
LHM10 & 76.8 & 22.8 & $x$ & 0.4 \\
HZM03 & 92.5 & 7.0 & $x$ & 0.5 \\
LLM05 & 58.2 & 24.2 & 15.2 & 2.4 \\
LLM08 & 65.0 & 17.9 & 16.3 & 0.8 \\
LLM01 & 67.8 & 18.3 & 12.4 & 1.5 \\
YZM12 & 67.3 & 32.6 & $x$ & 0.1 \\
STM05 & 67.7 & 30.8 & $x$ & 1.5 \\
\hline
\end{tabular}

See Figure 1 for sample location. Abbreviations: $V \rightarrow$ vitrinite content (vol.\%); $I \rightarrow$ inertinite content (vol.\%); $E \rightarrow$ Exinite content (vol.\%); MM $\rightarrow$ mineral matter content (vol.\%). $x=$ content $<0.1 \%$.

As for nonoriented samples, at least 20 points were measured with the same analytical method, and the mean statistical values of $R_{\max }$ and $R_{\min }$ were obtained.

3.3. Data Processing. On the basis of measured mean values, the values and occurrences of maximum reflectance $\left(R_{\max }\right)$, intermediate reflectance $\left(R_{\text {int }}\right)$, and minimum reflectance $\left(R_{\min }\right)$ axes may be obtained by solving ellipsoid equation in analytic geometry of space [35], which is the magnitudes and orientations of RIS. The computing method is in Figure 3 as follows:

$$
\lambda_{x}^{\prime} x^{2}+\lambda_{y}^{\prime} y^{2}+\lambda_{z}^{\prime} z^{2}-2 \gamma_{x y}^{\prime} x y-2 \gamma_{y z}^{\prime} y z-2 \gamma_{x z}^{\prime} z x=1
$$

where

$$
\begin{gathered}
\lambda_{x}^{\prime}=\frac{1}{\lambda_{x}}, \quad \lambda_{y}^{\prime}=\frac{1}{\lambda_{y}}, \quad \lambda_{z}^{\prime}=\frac{1}{\lambda_{z}}, \quad \gamma^{\prime}=\frac{\gamma}{\lambda}=\gamma \lambda^{\prime}, \\
\lambda_{x}^{\prime}=\frac{\cos ^{2} \bar{\theta}_{x}}{\left(\bar{R}_{\max }\right)_{x y}^{2}}+\frac{\sin ^{2} \bar{\theta}_{x}}{\left(\bar{R}_{\min }\right)_{x y}^{2}}, \\
\gamma_{x y}^{\prime}=\left[\begin{array}{c}
\lambda_{y}^{\prime}=\frac{\sin ^{2} \bar{\theta}_{x}}{\left(\bar{R}_{\max }\right)_{x y}^{2}}+\frac{\cos ^{2} \bar{\theta}_{x}}{\left(\bar{R}_{\min }\right)_{x y}^{2}}, \\
\left.\bar{R}_{\max }\right)_{x y}^{2}-\frac{\left(\bar{R}_{\min }\right)_{x y}^{2}}{\lambda_{y}^{\prime}}=\frac{\cos ^{2} \bar{\theta}_{y}}{\left(\bar{R}_{\max }\right)_{y z}^{2}}+\frac{\sin ^{2} \bar{\theta}_{y}}{\left(\bar{R}_{\min }\right)_{y z}^{2}}, \\
\lambda_{z}^{\prime}=\frac{\sin ^{2} \bar{\theta}_{y}}{\left(\bar{R}_{\max }\right)_{y z}^{2}}+\frac{\cos ^{2} \bar{\theta}_{z}}{\left(\bar{R}_{\min }\right)_{y z}^{2}},
\end{array}\right.
\end{gathered}
$$

$$
\begin{aligned}
& \gamma_{y z}^{\prime}=\left[\frac{1}{\left(\bar{R}_{\max }\right)_{y z}^{2}}-\frac{1}{\left(\bar{R}_{\min }\right)_{y z}^{2}}\right] * \sin \bar{\theta}_{y} * \cos \bar{\theta}_{y}, \\
& \lambda_{z}^{\prime}=\frac{\cos ^{2} \bar{\theta}_{z}}{\left(\bar{R}_{\max }\right)_{z x}^{2}}+\frac{\sin ^{2} \bar{\theta}_{z}}{\left(\bar{R}_{\min }\right)_{z x}^{2}}, \\
& \lambda_{x}^{\prime}=\frac{\sin ^{2} \bar{\theta}_{z}}{\left(\bar{R}_{\max }\right)_{z x}^{2}}+\frac{\cos ^{2} \bar{\theta}_{z}}{\left(\bar{R}_{\min }\right)_{z x}^{2}}, \\
& \gamma_{z x}^{\prime}=\left[\frac{1}{\left(\bar{R}_{\max }\right)_{z x}^{2}}-\frac{1}{\left(\bar{R}_{\min }\right)_{z x}^{2}}\right] * \sin \bar{\theta}_{z} * \cos \bar{\theta}_{z} .
\end{aligned}
$$

This ellipsoid equation has three eigenvalues, corresponding with the values of three RIS ellipsoid axes $\left(R_{\max }>\right.$ $\left.R_{\text {int }}>R_{\min }\right)$ :

$$
1+e_{i}=\sqrt{\lambda_{i}} ; \quad i=1,2,3
$$

The occurrence of three RIS ellipsoid axis is calculated according to the formula

$$
A_{i}=\frac{\arctan M_{i}}{L_{i}}, \quad B_{\mathrm{i}}=\arccos N_{i}, \quad i=1,2,3,
$$

where $A_{i}$ and $B_{i}$ represent the direction and dip angle of the axis in the coordinate system, respectively

$$
\begin{gathered}
L_{i}=\cos R_{i x}=\frac{X_{i}}{\sqrt{\lambda_{i}}} ; \quad M_{i}=\cos R_{i y}=\frac{Y_{i}}{\sqrt{\lambda_{\mathrm{i}}}}, \\
N_{i}=\cos R_{i z}=\frac{Z_{i}}{\sqrt{\lambda_{i}}}, \quad i=1,2,3, \\
X_{i}+Y_{i}+Z_{i}=\lambda_{i}, \\
\frac{X_{i}}{\lambda_{y}^{\prime} \lambda_{z}^{\prime}-\lambda_{i}^{\prime} \lambda_{y}^{\prime}-\lambda_{i}^{\prime} \lambda_{z}^{\prime}+\lambda_{i}^{\prime 2}-\gamma_{y z}^{\prime 2}} \\
=\frac{-Y_{i}}{-\gamma_{x y}^{\prime} \lambda_{z}^{\prime}+\gamma_{x y}^{\prime} \lambda_{i}^{\prime}-\gamma_{z x}^{\prime} \gamma_{y z}^{\prime}} \\
=\frac{-Z_{i}}{\gamma_{x y}^{\prime} \gamma_{y z}^{\prime}+\gamma_{z x}^{\prime} \lambda_{y}^{\prime}-\gamma_{z x}^{\prime} \lambda_{i}^{\prime}} .
\end{gathered}
$$

The geological occurrence of RIS ellipsoid axis $\left(\operatorname{Dir}_{i} \angle \operatorname{Dip}_{i}\right)$, however, needs a data conversion as follows:

$$
\begin{aligned}
& \text { if } B_{i} \geq 0, \quad \operatorname{Dir}_{i}=C_{i}-A_{i} \pm 360^{\circ}, \quad \operatorname{Dip}_{i}=B_{i} \text {, } \\
& \text { if } B_{i}<0, \quad \operatorname{Dir}_{i}=C_{i}-A_{i} \pm 180^{\circ}, \quad \operatorname{Dip}_{i}=-B_{i} \text {, }
\end{aligned}
$$

where $0<\operatorname{Dir}_{i}<360^{\circ}, 0<\operatorname{Dip}_{i}<90^{\circ}$; where $C_{i}$ represents the geological direction of arrowhead in Figure 2.

Therefore, the reflectance anisotropy (bireflectance $B_{w}$ and $R_{\mathrm{am}}$ coefficient values) and RIS shapes (such as $R_{\mathrm{ev}}, R_{\mathrm{st}}$ coefficient value, Flinn's parameters, etc.) can be determined. The details of the parameters are given as follows. 

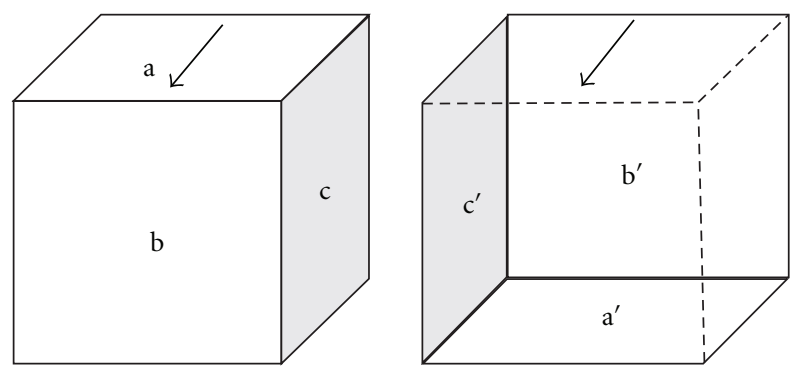

Figure 2: Diagram of three sections cut from oriented blocks. Arrowhead on the top surface of the block shows the spatial orientation. Surfaces marked with $\mathrm{a} / \mathrm{a}^{\prime}, \mathrm{b} / \mathrm{b}^{\prime}, \mathrm{c} / \mathrm{c}^{\prime}$ were mutually perpendicular with the surfaces a and $\mathrm{a}^{\prime}$ horizontal and $\mathrm{c}$ and $\mathrm{c}^{\prime}$ vertical and parallel to the arrowhead.

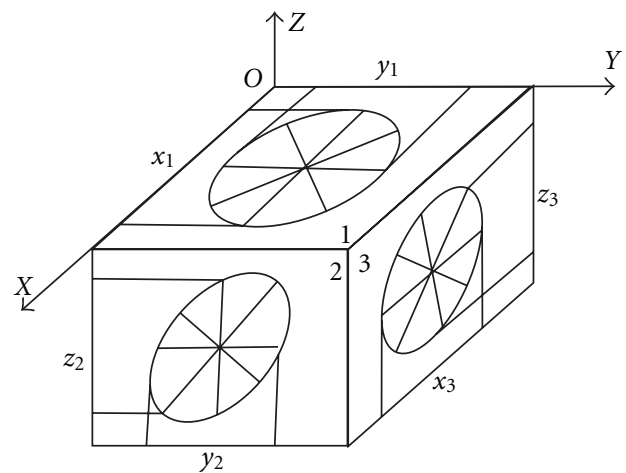

(a)

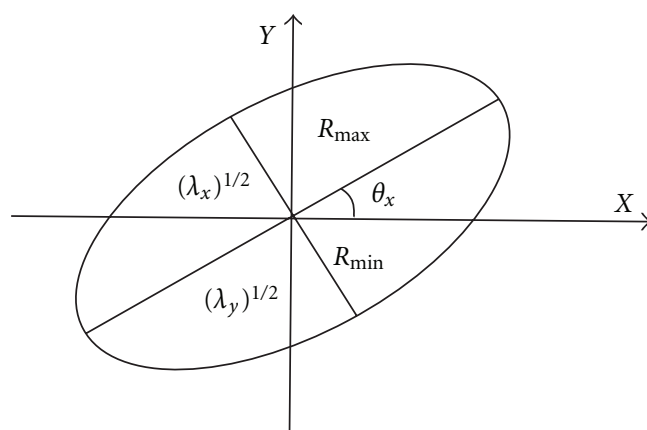

(b)

FIGURE 3: Coordinates and coal brick VR ellipses [11]. A coal sample brick was demonstrated in Figure 3(a), the measuring result were quantitatively represented in the $Y X Z$ coordinate system. The value and orientation of $R_{\max } / R_{\min }$ on each polished surface were shown on three mutually perpendicular cube face, represented by the long/minor axis of ellipse. For example, as shown in Figure 3(b), the measured value $\left(R_{X O Y \cdot \max }\right.$ and $\left.R_{X O Y \cdot \min }\right)$ and their orientations $\left(\theta_{x}\right)$ are expressed as their coordinates and the RIS ellipsoid equation can be built.

(1) $B_{w}$ coefficient value [22], representing bireflectance value, is calculated according to the formula.

$$
B_{\mathrm{w}}=R_{\max }-R_{\min } .
$$

$$
B_{w} / R_{\max }[21] \text { represents the bireflectance ratio. }
$$

(2) Flinn's parameter was firstly proposed for examining the geometry of three-dimensional homogeneous strain $[35,45]$. Formula of Ramsay was chosen here

$$
K=\frac{\varepsilon_{1}-\varepsilon_{2}}{\varepsilon_{2}-\varepsilon_{3}},
$$

where

$$
\varepsilon_{1}=\ln \left(R_{\max }\right), \quad \varepsilon_{2}=\ln \left(R_{\mathrm{int}}\right), \quad \varepsilon_{3}=\ln \left(R_{\min }\right) .
$$

(3) $R_{\mathrm{am}}$ coefficient value $[23,24]$, representing the RIS anisotropy magnitude, is calculated according to the formula

$$
R_{\mathrm{am}}=\left(x^{2}-y^{2}\right)^{1 / 2},
$$

where

$$
\begin{gathered}
x=\frac{R_{\mathrm{int}}}{R_{\max }+R_{\mathrm{int}}+R_{\min }}+\left[y+\frac{1}{3} \cos 30^{\circ}\right] \tan 30^{\circ}-\frac{1}{2}, \\
y=\left[\frac{R_{\max }}{\left(R_{\max }+R_{\mathrm{int}}+R_{\min }\right)}-\frac{1}{3}\right] \cos 30^{\circ} .
\end{gathered}
$$

This value is the distance between the plotted position of RIS and the position of an isotropic RIS, a single measure of anisotropy for all styles of RIS [23].Isotropic constituent of coal is characterized by $R_{\mathrm{am}}=0$. The higher coefficient value is, the stronger optical anisotropy will be. Typical $R_{\text {am }}$ values for raw vitrinites are from 0.03 to 0.05 and the value of 0.1 represents strong anisotropy of a constituent.

(4) $R_{\text {st }}$ coefficient value $[23,24]$, representing RIS style, is calculated according to the formula

$$
R_{\mathrm{st}}=30-\arctan \left(\frac{x}{y}\right)
$$

where $x$ and $y$ are determined in the same way as shown above. $R_{\mathrm{st}}$ values range from $(-30)$ to $(+30)$ and the RIS shape is described as 
$R_{\mathrm{st}}=(-30)$ : uniaxial negative; $R_{\mathrm{st}}=(+30)$ : uniaxial positive; $-30<R_{\mathrm{st}}<0$ : biaxial negative; $0<R_{\mathrm{st}}<$ +30 : biaxial positive; $R_{\mathrm{st}}=0$ : biaxial neutral.

(5) $R_{\mathrm{ev}}$ coefficient value $[23,24]$, representing the reflectance of equivalent volume of isotropic RIS, is calculated according to the formula

$$
R_{\mathrm{ev}}=\left(R_{\max } \times R_{\text {int }} \times R_{\min }\right)^{1 / 3} .
$$

\section{Results}

4.1. Anisotropic Properties of Nonoriented Samples. $R_{\max }$ and $R_{\min }$ of 11 non-oriented samples were measured and the anisotropic properties of the material such as $B_{w}$ and $B_{w} / R_{\max }$ were calculated as shown in Table 2.

4.2. Magnitude and Orientation of RIS. The magnitudes and orientations of RIS for 29 oriented samples were calculated by measuring the values and azimuths of the $R_{\max }$ and $R_{\min }$. Many of the coal samples suffered from tectonic deformation during coalification. The deformation types were identified by the proposed tectonic coals standard [38] and divided into three series: brittle-ductile transition, ductile shear, and brittle crush as shown in Table 3.

4.3. Anisotropic Property of Oriented Samples. Based on magnitudes and orientations of RIS, Levine's rank and Kilby's transformations are obtained as shown in Table 4.

\section{Discussion}

5.1. Major Facts Affecting VRA. Both temperature and stress have influences on modifying VRA. It is therefore necessary to estimate roughly the thermal effects during coalification before analyzing RIS.

In previous works, the mean random vitrinite reflectance $\left(R_{m} \%\right)$ shows a strong correlation $\left(r^{2}=0.7, n>600\right)$ with maximum burial temperature $\left(T_{\max }\right.$ in $\left.{ }^{\circ} \mathrm{C}\right)$. These data are modeled by the linear regression equation [46]:

$$
\ln \left(R_{m}\right)=0.0078 T_{\max }-1.2
$$

The conversion between $R_{\max }$ and $R_{\mathrm{m}}$ is following the analytical method described in GB/T 6948-2008 (equated with ISO7404/5 standard). On the basis of correlation given above, the maximum temperatures sustained during burial are estimated.

As shown in Table 5, the measured reflectance values range from $0.74 \%$ to 3.01 , indicating conversion of mediumvolatile bituminous coal to anthracite coal. Most of the studied samples experienced a maximum temperature between $120 \sim 20^{\circ} \mathrm{C}$, less than $290^{\circ} \mathrm{C}$ The available high temperaturepressure experiments on bituminous anthracite show that there is little change in vitrinite reflectance anisotropy under the temperature less than $400^{\circ} \mathrm{C}[47,48]$. It is reasonable to believe that the vitrinite reflectance anisotropy here was mainly caused by the tectonic differential stress.
TABLE 2: The vitrinite reflectance anisotropy of non-oriented samples, Huaibei coalfield.

\begin{tabular}{lccccccc}
\hline $\begin{array}{l}\text { Coal } \\
\text { mine }\end{array}$ & $\begin{array}{c}\text { Sample } \\
\text { number }\end{array}$ & $\begin{array}{c}\text { Coal } \\
\text { seam }\end{array}$ & $R_{\max }$ & $R_{\min }$ & $B_{w}$ & $B_{w} / R_{\max }$ & $R_{\max } / R_{\min }$ \\
\hline Linhuan & LH10 & 9 & 1.37 & 1.24 & 0.13 & 0.09 & 1.10 \\
Shitai & ST04 & 3 & 1.44 & 1.29 & 0.15 & 0.10 & 1.12 \\
Taoyuan & TY01 & 7 & 1.02 & 0.9 & 0.12 & 0.12 & 1.13 \\
Taoyuan & TY02 & 10 & 1.00 & 0.91 & 0.09 & 0.09 & 1.10 \\
Taoyuan & TY03 & 10 & 1.14 & 1.02 & 0.12 & 0.11 & 1.12 \\
Taoyuan & TY04 & 7 & 1.06 & 0.95 & 0.11 & 0.10 & 1.12 \\
Taoyuan & TY05 & 3 & 0.87 & 0.79 & 0.08 & 0.09 & 1.10 \\
Qidong & QD01 & 9 & 1.09 & 0.97 & 0.12 & 0.11 & 1.12 \\
Qidong & QD02 & 7 & 0.94 & 0.87 & 0.07 & 0.07 & 1.08 \\
Qidong & QD03 & 9 & 0.89 & 0.77 & 0.12 & 0.13 & 1.16 \\
Qidong & QD04 & 10 & 0.98 & 0.88 & 0.10 & 0.10 & 1.11 \\
\hline
\end{tabular}

Abbreviations: $R_{\max }$ : maximum reflectance; $R_{\text {int }}$ : intermediate reflectance; $R_{\min }$ : minimum reflectance; $B_{w}$ : bireflectance, $R_{\max }-R_{\min }$.

5.2. Magnitudes of RIS. The three sampling regions represent different stress-thermal environments and, therefore, the corresponding coal samples experienced different effects of deformation and metamorphism. The parameters of reflectance anisotropy (bireflectance $B_{w}$ and $R_{\text {am }}$ coefficient values) and RIS shapes (such as $R_{\mathrm{ev}}$ and $R_{\mathrm{st}}$ coefficient values, Flinn's parameters) are analyzed as follows.

5.2.1. Bireflectance. The bireflectance increases progressively with upgrading of coal rank under the heat treatment without differential stress involved. In that case, the bireflectance for the coal ranking from medium-volatile bituminous to anthracite coal should be at the same level and the $B_{w} / R_{\max }$ coefficient, representing bireflectance ratio, should be suitable for the bireflectance analysis among various coal ranks.

Relationships between $R_{\max }$ and $B_{w} / R_{\max }$ are shown in Figure 4 . The range of $R_{\max }$ value is $0.81 \sim 1.21 \%$ in Region $\mathrm{A}$ (Taoyuan mine, Qidong mine, and Xutuan mine) and 1.21 $3.13 \%$ in Region B (Linhuan mine and Haizi mine). This obvious difference above indicates that samples from Region $\mathrm{B}$ was dominated by the magmatic thermal activity. However, compared with Region A (Luling mine, Shitai mine, and Yangzhuang mine), samples in Region $\mathrm{C}$ where experienced extra effects of tectonic deformation and shearing heat, are manifested by the various $R_{\max }$ ranges of $0.83 \sim 1.72 \%$.

In contrast to Region $\mathrm{B}$, the $B_{w} / R_{\max }$ value in Region $\mathrm{C}$ and Region A simultaneously increased with the $R_{\max }$ and indicates that the reflectance in the two regions is dominated by the tectonic deformation and shearing heat.

The $95 \%$ confidence intervals of $B_{w} / R_{\max }$ value are $0.13 \pm$ 0.0195 in Region $\mathrm{A}$ and $0.23 \pm 0.0333$ in Region C. The difference between two regions represents the effects of tectonic stress. The same indictor in Region B is $0.17 \pm$ 0.0326 . The coal samples in the region were partly influenced by Mesozoic magmatism, and represent polarization of 
TABLe 3: Magnitude and orientation of RIS, Huaibei coalfield.

\begin{tabular}{|c|c|c|c|c|c|c|c|c|c|c|c|c|}
\hline \multirow{2}{*}{ Region } & \multirow{2}{*}{ Coal number } & \multirow{2}{*}{ Coal seam } & \multirow{2}{*}{ DT } & \multicolumn{3}{|c|}{$R_{\max }$ axes } & \multicolumn{3}{|c|}{$R_{\text {int }}$ axes } & \multicolumn{3}{|c|}{$R_{\min }$ axes } \\
\hline & & & & Value & Strike & Dip & Value & Strike & Dip & Value & Strike & Dip \\
\hline \multirow{8}{*}{ Region A } & TYM03 & 8 & $\mathrm{BD}$ & 1.01 & $41^{\circ}$ & $81^{\circ}$ & 0.95 & $177^{\circ}$ & $21^{\circ}$ & 0.77 & $266^{\circ}$ & $6^{\circ}$ \\
\hline & TYM04 & 8 & $\mathrm{BC}$ & 1.00 & $323^{\circ}$ & $69^{\circ}$ & 0.90 & $153^{\circ}$ & $55^{\circ}$ & 0.81 & $37^{\circ}$ & $44^{\circ}$ \\
\hline & TYM06 & 10 & $\mathrm{BC}$ & 0.87 & $234^{\circ}$ & $89^{\circ}$ & 0.85 & $28^{\circ}$ & $49^{\circ}$ & 0.74 & $160^{\circ}$ & $16^{\circ}$ \\
\hline & TYM07 & 10 & $\mathrm{BC}$ & 0.79 & $164^{\circ}$ & $4^{\circ}$ & 0.75 & $291^{\circ}$ & $72^{\circ}$ & 0.72 & $82^{\circ}$ & $89^{\circ}$ \\
\hline & XTM01 & 7 & $\mathrm{BC}$ & 1.11 & $151^{\circ}$ & $69^{\circ}$ & 0.99 & $239^{\circ}$ & $36^{\circ}$ & 0.89 & $37^{\circ}$ & $63^{\circ}$ \\
\hline & XTM02 & 7 & $\mathrm{BD}$ & 1.11 & $106^{\circ}$ & $87^{\circ}$ & 1.01 & $157^{\circ}$ & $1^{\circ}$ & 0.97 & $248^{\circ}$ & $77^{\circ}$ \\
\hline & ХTM06 & 7 & DS & 1.13 & $248^{\circ}$ & $85^{\circ}$ & 1.07 & $107^{\circ}$ & $40^{\circ}$ & 0.98 & $25^{\circ}$ & $63^{\circ}$ \\
\hline & XTM07 & 7 & $\mathrm{BC}$ & 1.11 & $242^{\circ}$ & $64^{\circ}$ & 1.05 & $126^{\circ}$ & $4^{\circ}$ & 0.98 & $60^{\circ}$ & $45^{\circ}$ \\
\hline \multirow{15}{*}{ Region B } & LHM02 & 7 & DS & 1.31 & $339^{\circ}$ & $87^{\circ}$ & 1.26 & $250^{\circ}$ & $67^{\circ}$ & 1.14 & $139^{\circ}$ & $86^{\circ}$ \\
\hline & LHM03 & 7 & DS & 1.55 & $300^{\circ}$ & $88^{\circ}$ & 1.25 & $108^{\circ}$ & $6^{\circ}$ & 1.17 & $196^{\circ}$ & $54^{\circ}$ \\
\hline & LHM04 & 9 & $\mathrm{BD}$ & 1.46 & $256^{\circ}$ & $54^{\circ}$ & 1.40 & $344^{\circ}$ & $22^{\circ}$ & 1.29 & $82^{\circ}$ & $67^{\circ}$ \\
\hline & LHM05 & 9 & $\mathrm{BD}$ & 3.09 & $56^{\circ}$ & $74^{\circ}$ & 2.69 & $310^{\circ}$ & $54^{\circ}$ & 2.36 & $222^{\circ}$ & $49^{\circ}$ \\
\hline & LHM09 & 9 & $\mathrm{BD}$ & 1.44 & $295^{\circ}$ & $56^{\circ}$ & 1.31 & $174^{\circ}$ & $36^{\circ}$ & 1.15 & $25^{\circ}$ & $82^{\circ}$ \\
\hline & LHM12 & 10 & $\mathrm{BD}$ & 1.24 & $62^{\circ}$ & $85^{\circ}$ & 1.15 & $196^{\circ}$ & $5^{\circ}$ & 1.10 & $272^{\circ}$ & $82^{\circ}$ \\
\hline & LHM14 & 10 & $\mathrm{BD}$ & 1.50 & $344^{\circ}$ & $15^{\circ}$ & 1.36 & $205^{\circ}$ & $72^{\circ}$ & 1.18 & $73^{\circ}$ & $55^{\circ}$ \\
\hline & LHC01* & - & - & 1.37 & $337^{\circ}$ & $41^{\circ}$ & 1.15 & $246^{\circ}$ & $1^{\circ}$ & 1.13 & $156^{\circ}$ & $41^{\circ}$ \\
\hline & HZM03 & 10 & $\mathrm{BC}$ & 1.92 & $121^{\circ}$ & $32^{\circ}$ & 1.70 & $47^{\circ}$ & $89^{\circ}$ & 1.63 & $222^{\circ}$ & $35^{\circ}$ \\
\hline & HZM04 & 10 & BC & 2.01 & $98^{\circ}$ & $27^{\circ}$ & 1.98 & $333^{\circ}$ & $82^{\circ}$ & 1.82 & $186^{\circ}$ & $89^{\circ}$ \\
\hline & HZM10 & 8 & DS & 2.66 & $332^{\circ}$ & $33^{\circ}$ & 2.54 & $233^{\circ}$ & $16^{\circ}$ & 2.51 & $151^{\circ}$ & $84^{\circ}$ \\
\hline & HZC02* & - & - & 1.46 & $93^{\circ}$ & $26^{\circ}$ & 1.32 & $345^{\circ}$ & $31^{\circ}$ & 1.17 & $214^{\circ}$ & $46^{\circ}$ \\
\hline & HZC03* & - & - & 1.45 & $3^{\circ}$ & $36^{\circ}$ & 1.26 & $101^{\circ}$ & $11^{\circ}$ & 1.13 & $205^{\circ}$ & $51^{\circ}$ \\
\hline & BSC04* & - & - & 2.61 & $24^{\circ}$ & $1^{\circ}$ & 2.16 & $289^{\circ}$ & $87^{\circ}$ & 2.08 & $114^{\circ}$ & $3^{\circ}$ \\
\hline & BSC05* & - & - & 2.54 & $249^{\circ}$ & $8^{\circ}$ & 2.21 & $343^{\circ}$ & $26^{\circ}$ & 1.96 & $149^{\circ}$ & $62^{\circ}$ \\
\hline \multirow{12}{*}{ Region C } & YZM11 & 3 & $\mathrm{BC}$ & 1.70 & $30^{\circ}$ & $77^{\circ}$ & 1.59 & $160^{\circ}$ & $89^{\circ}$ & 1.34 & $215^{\circ}$ & $63^{\circ}$ \\
\hline & YZM14 & 3 & BC & 1.69 & $132^{\circ}$ & $88^{\circ}$ & 1.61 & $248^{\circ}$ & $29^{\circ}$ & 1.38 & $335^{\circ}$ & $88^{\circ}$ \\
\hline & YZM16 & 3 & $\mathrm{BC}$ & 1.82 & $164^{\circ}$ & $24^{\circ}$ & 1.60 & $3^{\circ}$ & $65^{\circ}$ & 1.30 & $254^{\circ}$ & $74^{\circ}$ \\
\hline & STM01 & 3 & $\mathrm{BD}$ & 1.52 & $128^{\circ}$ & $84^{\circ}$ & 1.47 & $4^{\circ}$ & $11^{\circ}$ & 1.21 & $275^{\circ}$ & $75^{\circ}$ \\
\hline & STM02 & 3 & $\mathrm{BC}$ & 1.41 & $215^{\circ}$ & $33^{\circ}$ & 1.36 & $17^{\circ}$ & $83^{\circ}$ & 1.10 & $97^{\circ}$ & $42^{\circ}$ \\
\hline & STM03 & 3 & $\mathrm{BD}$ & 1.72 & $94^{\circ}$ & $2^{\circ}$ & 1.25 & $209^{\circ}$ & $64^{\circ}$ & 1.18 & $16^{\circ}$ & $2^{\circ}$ \\
\hline & STC06* & - & - & 1.52 & $186^{\circ}$ & $22^{\circ}$ & 1.37 & $277^{\circ}$ & $3^{\circ}$ & 1.19 & $15^{\circ}$ & $67^{\circ}$ \\
\hline & LLM03 & 8 & $\mathrm{BD}$ & 1.06 & $47^{\circ}$ & $50^{\circ}$ & 0.99 & $261^{\circ}$ & $38^{\circ}$ & 0.88 & $171^{\circ}$ & $77^{\circ}$ \\
\hline & LLM05 & 8 & DS & 0.84 & $322^{\circ}$ & $74^{\circ}$ & 0.76 & $247^{\circ}$ & $17^{\circ}$ & 0.59 & $118^{\circ}$ & $63^{\circ}$ \\
\hline & LLM07 & 10 & $\mathrm{BC}$ & 0.95 & $156^{\circ}$ & $45^{\circ}$ & 0.86 & $345^{\circ}$ & $47^{\circ}$ & 0.74 & $256^{\circ}$ & $57^{\circ}$ \\
\hline & LLM08 & 10 & $\mathrm{BC}$ & 0.83 & $146^{\circ}$ & $18^{\circ}$ & 0.80 & $357^{\circ}$ & $79^{\circ}$ & 0.75 & $235^{\circ}$ & $83^{\circ}$ \\
\hline & LLM10 & 8 & DS & 1.11 & $307^{\circ}$ & $67^{\circ}$ & 0.92 & $35^{\circ}$ & $42^{\circ}$ & 0.83 & $168^{\circ}$ & $68^{\circ}$ \\
\hline
\end{tabular}

* Data complied from [18].

Abbreviations: DT: deformation type; BD: brittle-ductile transition; DS: ductile shear; BC: brittle crush; $R_{\max }$ : maximum reflectance; $R_{\text {int }}$ : intermediate reflectance; $R_{\min }$ : minimum reflectance.

$R_{\mathrm{o}}$ value. Meanwhile, some strata underwent stronger deformation with increasing $B_{w} / R_{\max }$ values.

5.2.2. Reflectance of Equivalent Volume Isotropic RIS. RIS parameter $R_{\mathrm{ev}}$, the reflectance of the isotropic RIS of equivalent volume, as a result of the chemical structure ordering during heating, is suggested to characterize the basic structure unites (BSU) [49].

As shown in Figure 5, positive linear regression relationships between $R_{\max }$ and $R_{\mathrm{ev}}\left(r^{2}\right)$ for Regions $\mathrm{A}, \mathrm{B}$, and $\mathrm{C}$ are $0.956,0.980$, and 0.965 , respectively. The correlations between $R_{\mathrm{ev}}$ values and the hydrogen contents $\left(\mathrm{H}^{\mathrm{daf}}\right)$ have 
TABLE 4: Calculated results of RIS parameters, Huaibei coalfield.

\begin{tabular}{|c|c|c|c|c|c|c|c|c|c|c|c|c|}
\hline \multirow{2}{*}{ Region } & \multirow{2}{*}{ Coal number } & \multirow{2}{*}{ Coal seam } & \multirow{2}{*}{ DT } & \multirow{2}{*}{$R_{\mathrm{st}}$} & \multirow{2}{*}{$R_{\mathrm{am}}$} & \multirow{2}{*}{$R_{\mathrm{ev}}$} & \multirow{2}{*}{$B_{w}$} & \multirow{2}{*}{$B_{w} / R_{\max }$} & \multicolumn{3}{|c|}{ Axis ratio } & \multirow{2}{*}{ K } \\
\hline & & & & & & & & & $R_{\max } / R_{\text {int }}$ & $R_{\text {int }} / R_{\min }$ & $R_{\max } / R_{\min }$ & \\
\hline \multirow{8}{*}{ Region A } & TYM03 & 8 & $\mathrm{BD}$ & -14.43 & 0.05 & 0.90 & 0.24 & 0.24 & 1.07 & 1.23 & 1.31 & 0.33 \\
\hline & TYM04 & 8 & $\mathrm{BC}$ & 1.06 & 0.04 & 0.90 & 0.19 & 0.19 & 1.11 & 1.11 & 1.23 & 0.96 \\
\hline & TYM06 & 10 & $\mathrm{BC}$ & -20.43 & 0.03 & 0.82 & 0.13 & 0.15 & 1.03 & 1.15 & 1.18 & 0.20 \\
\hline & TYM07 & 10 & $\mathrm{BC}$ & -0.05 & 0.02 & 0.75 & 0.07 & 0.09 & 1.05 & 1.05 & 1.10 & 0.95 \\
\hline & XTM01 & 7 & $\mathrm{BC}$ & 2.52 & 0.04 & 0.99 & 0.23 & 0.20 & 1.12 & 1.12 & 1.26 & 1.04 \\
\hline & XTM02 & 7 & $\mathrm{BD}$ & 14.66 & 0.03 & 1.03 & 0.14 & 0.12 & 1.10 & 1.04 & 1.14 & 2.49 \\
\hline & XTM06 & 7 & DS & -6.05 & 0.03 & 1.06 & 0.16 & 0.14 & 1.06 & 1.10 & 1.16 & 0.64 \\
\hline & XTM07 & 7 & $\mathrm{BC}$ & -4.73 & 0.02 & 1.05 & 0.12 & 0.11 & 1.05 & 1.07 & 1.13 & 0.71 \\
\hline \multirow{15}{*}{ Region B } & LHM02 & 7 & DS & -12.79 & 0.03 & 1.23 & 0.18 & 0.13 & 1.04 & 1.11 & 1.16 & 0.41 \\
\hline & LHM03 & 7 & DS & 17.42 & 0.06 & 1.31 & 0.38 & 0.24 & 1.23 & 1.07 & 1.32 & 2.93 \\
\hline & LHM04 & 9 & $\mathrm{BD}$ & -9.73 & 0.02 & 1.38 & 0.17 & 0.12 & 1.04 & 1.08 & 1.13 & 0.51 \\
\hline & LHM05 & 9 & $\mathrm{BD}$ & 2.89 & 0.05 & 2.70 & 0.72 & 0.23 & 1.15 & 1.14 & 1.31 & 1.04 \\
\hline & LHM09 & 9 & $\mathrm{BD}$ & -3.89 & 0.04 & 1.29 & 0.30 & 0.21 & 1.10 & 1.15 & 1.26 & 0.70 \\
\hline & LHM12 & 10 & $\mathrm{BD}$ & 12.26 & 0.02 & 1.16 & 0.14 & 0.11 & 1.08 & 1.04 & 1.13 & 2.08 \\
\hline & LHM14 & 10 & $\mathrm{BD}$ & -4.52 & 0.03 & 1.34 & 0.33 & 0.22 & 1.10 & 1.16 & 1.28 & 0.67 \\
\hline & LHC01* & - & - & 25.69 & 0.04 & 1.21 & 0.24 & 0.18 & 1.19 & 1.02 & 1.21 & 9.98 \\
\hline & HZM03 & 10 & $\mathrm{BC}$ & 15.63 & 0.03 & 1.75 & 0.30 & 0.15 & 1.13 & 1.05 & 1.18 & 2.65 \\
\hline & HZM04 & 10 & BC & -21.15 & 0.02 & 1.94 & 0.19 & 0.09 & 1.02 & 1.09 & 1.10 & 0.19 \\
\hline & HZM10 & 8 & DS & 18.44 & 0.01 & 2.57 & 0.15 & 0.06 & 1.05 & 1.01 & 1.06 & 3.63 \\
\hline & $\mathrm{HZC} 02^{*}$ & - & - & -1.14 & 0.04 & 1.31 & 0.29 & 0.20 & 1.11 & 1.13 & 1.25 & 0.84 \\
\hline & HZC03* & - & - & 6.18 & 0.05 & 1.27 & 0.32 & 0.22 & 1.15 & 1.12 & 1.28 & 1.29 \\
\hline & BSC04* & - & - & 21.95 & 0.05 & 2.27 & 0.53 & 0.20 & 1.21 & 1.04 & 1.25 & 5.01 \\
\hline & BSC05* & - & - & 4.55 & 0.05 & 2.22 & 0.58 & 0.23 & 1.15 & 1.13 & 1.30 & 1.16 \\
\hline \multirow{12}{*}{ Region C } & LLM03 & 8 & $\mathrm{BC}$ & -7.01 & 0.04 & 0.98 & 0.18 & 0.17 & 1.07 & 1.12 & 1.21 & 0.59 \\
\hline & LLM05 & 8 & $\mathrm{BC}$ & -11.51 & 0.07 & 0.72 & 0.24 & 0.29 & 1.10 & 1.28 & 1.41 & 0.40 \\
\hline & LLM07 & 10 & $\mathrm{BC}$ & -6.37 & 0.05 & 0.85 & 0.21 & 0.22 & 1.10 & 1.17 & 1.28 & 0.60 \\
\hline & LLM08 & 10 & $\mathrm{BD}$ & -8.05 & 0.02 & 0.79 & 0.08 & 0.10 & 1.04 & 1.07 & 1.11 & 0.58 \\
\hline & LLM10 & 8 & $\mathrm{BC}$ & 11.71 & 0.06 & 0.94 & 0.27 & 0.25 & 1.20 & 1.11 & 1.33 & 1.84 \\
\hline & YZM11 & 3 & $\mathrm{BC}$ & -12.87 & 0.05 & 1.54 & 0.37 & 0.21 & 1.07 & 1.19 & 1.27 & 0.38 \\
\hline & YZM14 & 3 & $\mathrm{BC}$ & -15.35 & 0.04 & 1.55 & 0.32 & 0.19 & 1.05 & 1.17 & 1.23 & 0.32 \\
\hline & YZM16 & 3 & $\mathrm{BC}$ & -4.68 & 0.06 & 1.56 & 0.53 & 0.29 & 1.14 & 1.23 & 1.41 & 0.63 \\
\hline & STM01 & 3 & $\mathrm{BD}$ & -21.59 & 0.05 & 1.39 & 0.32 & 0.21 & 1.03 & 1.22 & 1.26 & 0.17 \\
\hline & STM02 & 3 & $\mathrm{BC}$ & -20.95 & 0.05 & 1.28 & 0.31 & 0.22 & 1.04 & 1.24 & 1.29 & 0.18 \\
\hline & STM03 & 3 & $\mathrm{BD}$ & 23.20 & 0.08 & 1.37 & 0.54 & 0.31 & 1.38 & 1.06 & 1.46 & 5.57 \\
\hline & STC06* & - & - & -3.00 & 0.05 & 1.35 & 0.33 & 0.22 & 1.11 & 1.15 & 1.28 & 0.74 \\
\hline
\end{tabular}

${ }^{*}$ Data complied from [18] except for the coal seam and deformation type of these four samples. Abbreviations: BD: brittle-ductile transition; DS: ductile shear; BC: brittle crush; DT: deformation type; $R_{\max }$ : maximum reflectance; $R_{\text {int }}$ : intermediate reflectance; $R_{\min }:$ minimum reflectance; $B_{w}$ : bireflectance, $R_{\max }-R_{\min } ; \mathrm{K}$ : Flinn's parameter, $\left(\varepsilon_{1}-\varepsilon_{2}\right) /\left(\varepsilon_{2}-\varepsilon_{3}\right)$, where $\varepsilon_{1}=\ln \left(R_{\max }\right), \varepsilon_{2}=\ln \left(R_{\mathrm{int}}\right), \varepsilon_{3}=\ln \left(R_{\min }\right) ; R_{\mathrm{am}}$ : RIS anisotropy magnitude, $\left(x^{2}-y^{2}\right)^{1 / 2} ; R_{\mathrm{st}} \rightarrow R_{\mathrm{IS}}$ style, $30-\arctan (x / y)$; $R_{\mathrm{ev}}$ : reflectance of equivalent volume isotropic RIS, $\left(R_{\max } \times R_{\text {int }} \times R_{\min }\right)^{1 / 3}$; where $x=R_{\text {int }} /\left(R_{\max }+R_{\text {int }}+R_{\min }\right)+\left[y+1 / 3\right.$ cos $\left.30^{\circ}\right] \times$ $\tan 30^{\circ}-1 / 2, y=\left[R_{\max } /\left(R_{\max }+R_{\text {int }}+R_{\min }\right)-1 / 3\right] \times \cos 30^{\circ}$. 
TABle 5: Maximum temperatures sustained during burial, Upper Permian strata, Huaibei coalfield.

\begin{tabular}{|c|c|c|c|c|c|c|c|c|}
\hline \multicolumn{3}{|c|}{ Region A } & \multicolumn{3}{|c|}{ Region B } & \multicolumn{3}{|c|}{ Region C } \\
\hline Number & $R_{\max }$ & $T_{\max }\left({ }^{\circ} \mathrm{C}\right)$ & Noumber & $R_{\max }$ & $T_{\max }\left({ }^{\circ} \mathrm{C}\right)$ & Number & $R_{\max }$ & $T_{\max }\left({ }^{\circ} \mathrm{C}\right)$ \\
\hline TYM03 & 1.01 & 147 & LHM02 & 1.31 & 180 & STM01 & 1.52 & 200 \\
\hline TYM04 & 0.94 & 138 & LHM03 & 1.52 & 200 & STM02 & 1.41 & 190 \\
\hline TYM06 & 0.88 & 129 & LHM04 & 1.41 & 190 & STM03 & 1.72 & 215 \\
\hline TYM07 & 0.81 & 119 & LHM05 & 3.13 & 283 & STC06* & 1.52 & 200 \\
\hline TY01 & 1.02 & 148 & LHM09 & 1.34 & 183 & YZM11 & 1.70 & 214 \\
\hline TY02 & 1.00 & 146 & LHM12 & 1.21 & 170 & YZM14 & 1.69 & 213 \\
\hline TY03 & 1.14 & 163 & LHM14 & 1.37 & 186 & YZM16 & 1.82 & 223 \\
\hline TY04 & 1.06 & 153 & LHC01* & 1.37 & 186 & ST01 & 1.44 & 193 \\
\hline TY05 & 0.87 & 128 & LH01 & 1.37 & 186 & LLM03 & 1.11 & 159 \\
\hline QD01 & 1.09 & 157 & HZM03 & 1.82 & 223 & LLM05 & 0.83 & 122 \\
\hline QD02 & 0.94 & 138 & HZM04 & 1.99 & 234 & LLM07 & 0.96 & 141 \\
\hline QD03 & 0.89 & 131 & HZM10 & 2.58 & 261 & LLM08 & 0.88 & 129 \\
\hline QD04 & 0.98 & 143 & $\mathrm{HZC} 02 *$ & 1.46 & 194 & LLM10 & 1.04 & 151 \\
\hline XTM01 & 1.13 & 162 & HZC03* & 1.45 & 193 & & & \\
\hline XTM02 & 1.12 & 160 & BSC $04^{*}$ & 2.61 & 263 & & & \\
\hline XTM06 & 1.13 & 162 & BSC05* & 2.54 & 260 & & & \\
\hline XTM07 & 1.21 & 170 & & & & & & \\
\hline
\end{tabular}

* Data complied from [18]. During the calculation, $R_{\max }$ is converted into random vitrinite reflectance at first, and then the maximum buried temperature are obtained by the formula given above. Abbreviations: $R_{\max }$ : maximum reflectance; $T_{\max }$ : maximum buried temperature.

been verified that the $R_{\mathrm{ev}}$ depends on the chemical composition of anthracites rather than the three-dimensional BSU [30]. Since the chemical composition and structure mainly evolved under the effect of temperature and coincided with the results, the linear- regression slope of Region B seems to be mainly influenced by the thermal effect.

5.2.3. RIS Style and Anisotropy Magnitude. The coefficient values of $R_{\mathrm{st}}$ and $R_{\mathrm{am}}$ construct polar scatter plots proposed by [23], and the three-dimensional style and anisotropy magnitude of RIS can be analyzed together. As shown in Figure 6(a), samples from Region A and C are characterized by substantial RIS style of biaxial negative $\left(R_{\mathrm{st}}\right.$ ranges between $-30 \sim 15)$. The anisotropy magnitude in Region C ( $R_{\mathrm{am}}$ ranges between $0.04 \sim 0.08$ ), however, is higher than that in Region A ( $R_{\mathrm{am}}$ ranges between 0.02 0.04), which coincides with the distribution of bireflectance ratio. Conversely, as shown in Figure 6(b), the samples from Region $\mathrm{B}$ are characterized by significant biaxial positive character or unconspicuous biaxial negative $\left(R_{\mathrm{st}}\right.$ ranges between $-15 \sim$ $30)$ and the anisotropy magnitude $\left(R_{\mathrm{am}}\right)$ is various, ranging from 0.02 to 0.06 .

5.2.4. RIS-Logarithmic Flinn Diagrams. For a more complete characterization of the optical properties of both raw and carbonized anthracites, the modified Flinn's $K$ parameters [35], related to the anisotropy as well as the optical character, are also calculated and shown in. The samples from Region $\mathrm{C}$ and $\mathrm{A}$ are characterized by evolvement of RIS style from constriction types to flattening types $(0<k<1$ shown in
Figure 7(a)). However, RIS styles of the samples from Region $B$ are complicated and various (as shown in Figure 7(b)), corresponding to plane strain in finite strain analysis.

5.2.5. RIS Anisotropy Evolution Stages . The deformation path of finite strain analyses proposed by Ramsay suggested that the cleavage is developed by the route of "sphere types $\rightarrow$ uniaxial oblate types $\rightarrow$ uniaxial prolate types $\rightarrow$ uniaxial oblate types $\rightarrow$ flattening types". The anisotropic coal samples may have the same evolution process. A related evolutionary path of RIS style during coalification was reported by Levine [15] and the stages are given as follows.

The first stage was after the deposition. The peat was subjected to mild geothermal process due to broad regional subsidence and burial of overlying rocks. During this period, the ambient geologic stresses were nontectonic and only due to vertical static pressure loading by the overlying strata. Owing to the vertical downward lithostatic pressure, RIS would show the style of uniaxial negative. At the second stage, the anisotropic strain developed by tectonic differential stress (in a lateral direction) and lithostatic pressure (in the vertical direction) and the coal seams would suffer from extrusion in two directions and the anisotropic RIS represents the style of biaxial positive. At the third stage, with the increase of buried depth (more than $1000 \mathrm{~m}$ ), the pressure on the coal seams from the overlying strata may approximately represent as isotropic hydrostatic pressure (Heim's hypothesis). The tectonic differential stress is upgraded with the enhancement of tectonic agency. All of these factors would make the anisotropic RIS style as biaxial negative. 


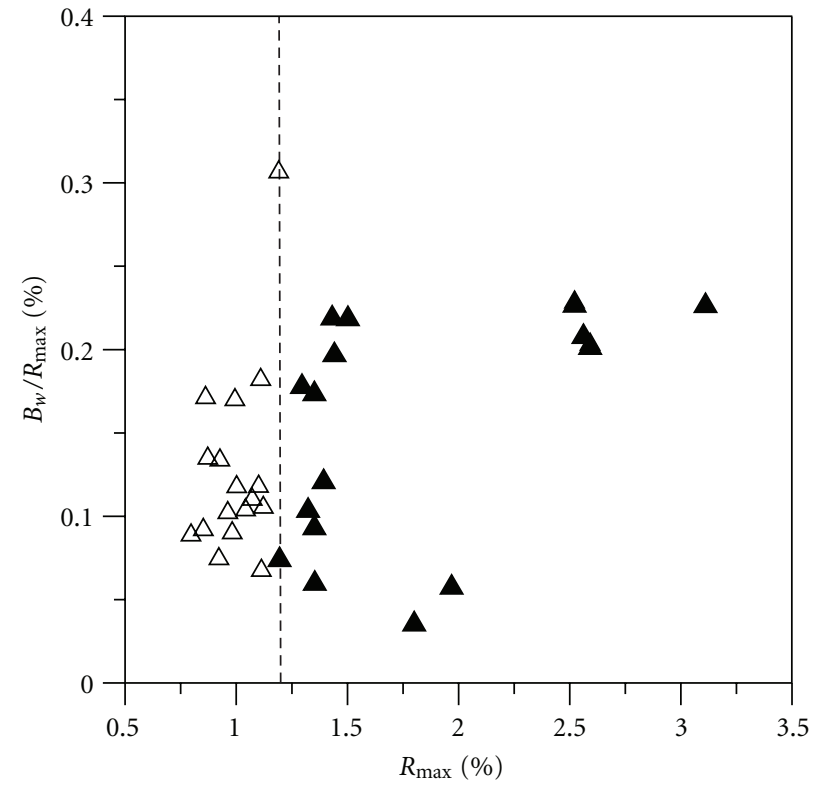

$\triangle$ Normal belt

\ Magmatic belt

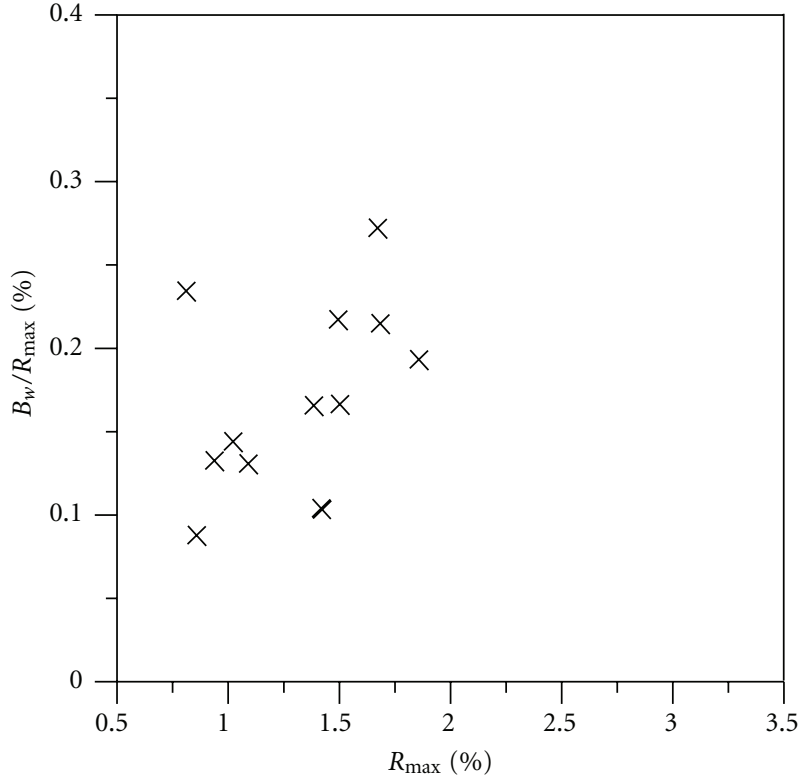

$\times$ Nappe belt

(a)

(b)

Figure 4: Correlations between $R_{\max }$ and $B_{w} / R_{\max }$ for the anthracites. $R_{\max }$ : maximum reflectance; $B_{w} / R_{\max }:$ bireflectance ratio.

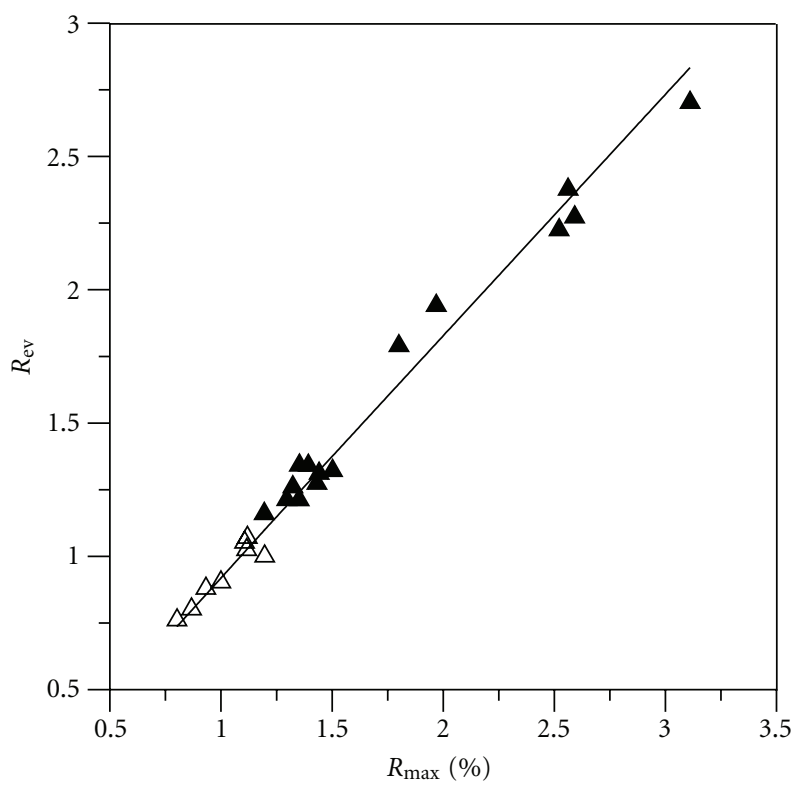

$\triangle$ Normal belt

$\Delta$ Magmatic belt

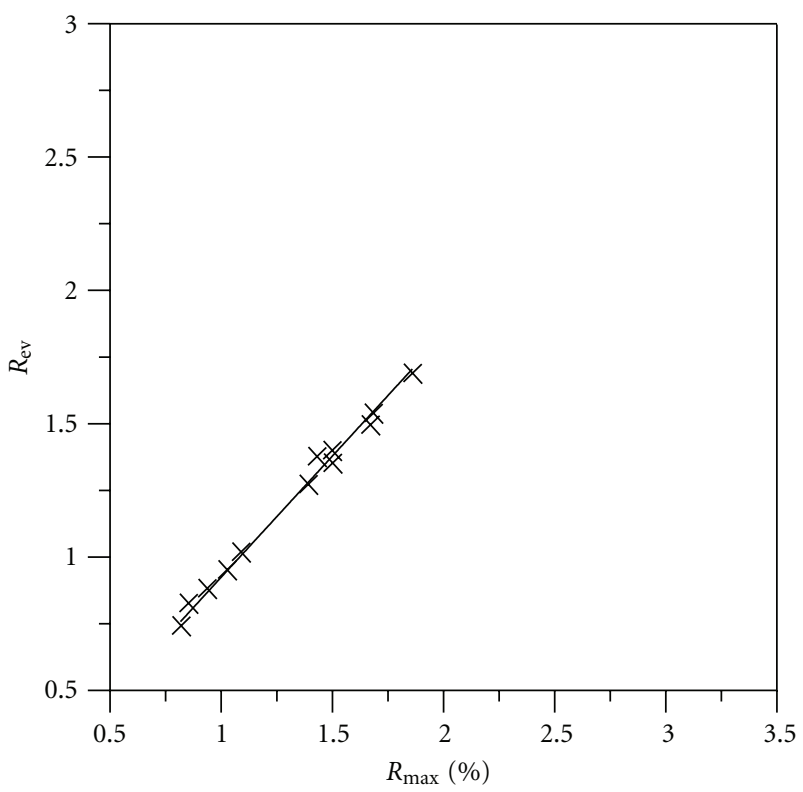

$\times$ Nappe belt

(a)

(b)

FIGURE 5: Correlation between $R_{\max }$ and $R_{\mathrm{ev}}$ for the anthracites. Region A: $y=(0.866 * x)+0.057$ (coef. of determination, $r^{2}=0.956$ ); Region B: $y=0.888 x+0.031$ (coef. of determination, $\left.r^{2}=0.980\right)$; Region C: $y=(0.838 * x)+0.063$ (coef. of determination, $r^{2}=0.965$ ); $R_{\max }$ : maximum reflectance; $R_{\mathrm{ev}}$ : Reflectance of equivalent volume isotropic RIS, $\left(R_{\max } \times R_{\mathrm{int}} \times R_{\min }\right)^{1 / 3}$. 


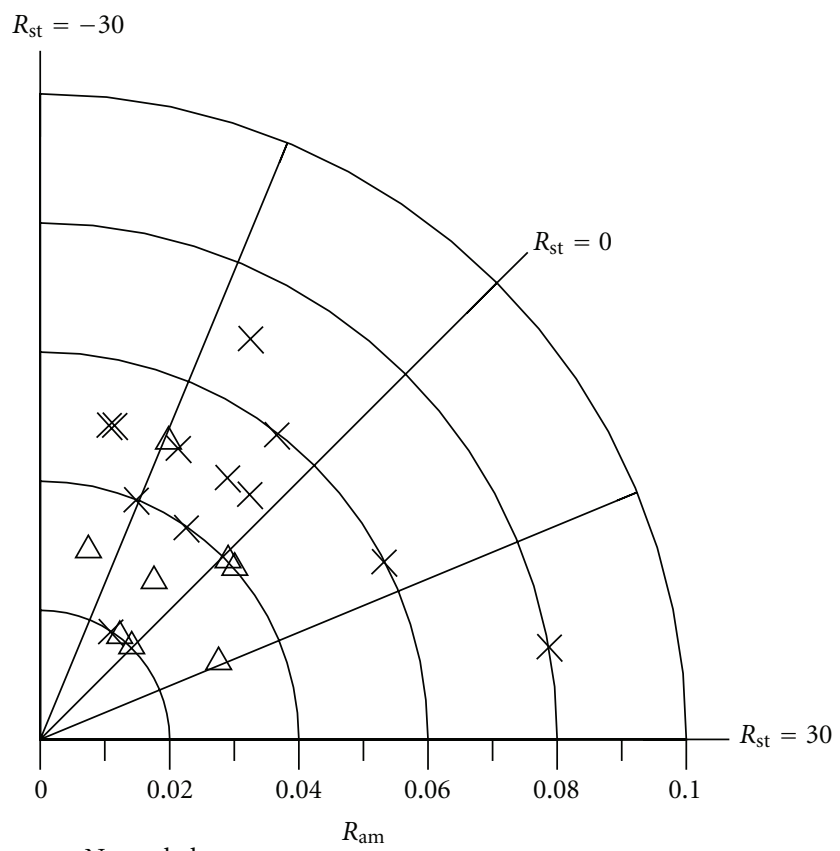

$\times$ Nappe belt

$\triangle$ Normal belt

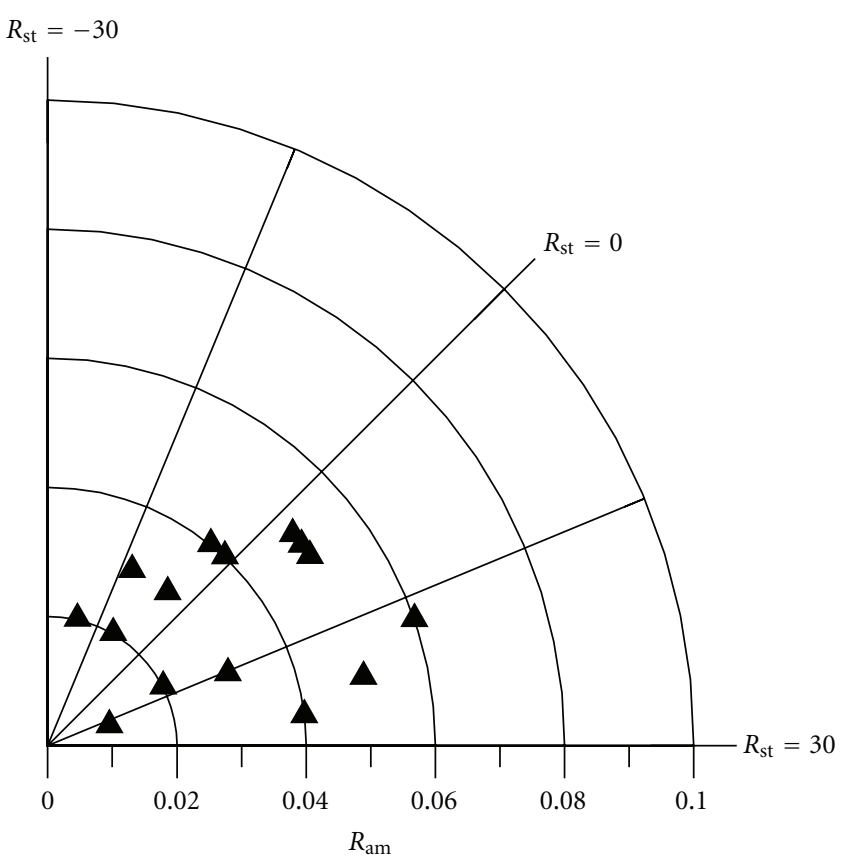

$\Delta$ Magmatic belt

(a)

(b)

FIGURE 6: $R_{\mathrm{st}}-R_{\mathrm{am}}$ polar plots of anthracites. $R_{\mathrm{am}}$-RIS anisotropy magnitude, $\left(x^{2}-y^{2}\right)^{1 / 2} ; R_{\mathrm{st}}-\mathrm{RIS}$ style, 30 - $\arctan (x / y)$ where $x=R_{\mathrm{int}} /\left(R_{\max }+\right.$ $\left.R_{\text {int }}+R_{\min }\right)+\left[y+1 / 3 \cos 30^{\circ}\right] \times \tan 30^{\circ}-1 / 2, y=\left[R_{\max } /\left(R_{\max }+R_{\text {int }}+R_{\min }\right)-1 / 3\right] \times \cos 30^{\circ}$; RIS shape described as $-30<R_{\mathrm{st}}<0$-biaxial negative; $0<R_{\mathrm{st}}<+30$-biaxial positive; $R_{\mathrm{st}}=(-30)$ uniaxial negative; $R_{\mathrm{st}}=(+30)$ uniaxial positive, $R_{\mathrm{st}}=0$-biaxial neutral.

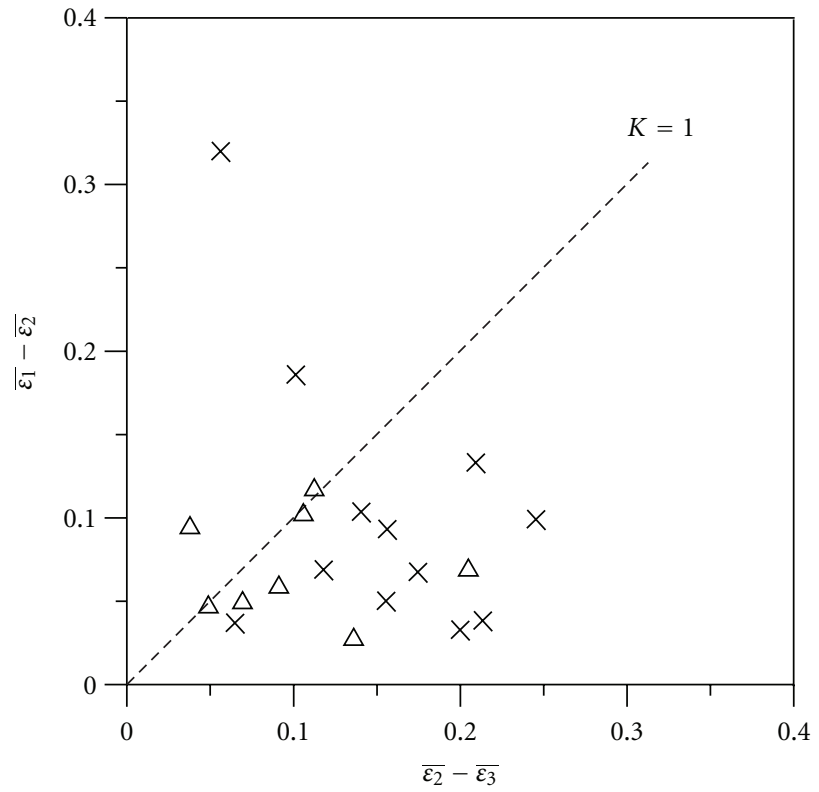

$\times$ Nappe belt $\triangle$ Normal belt

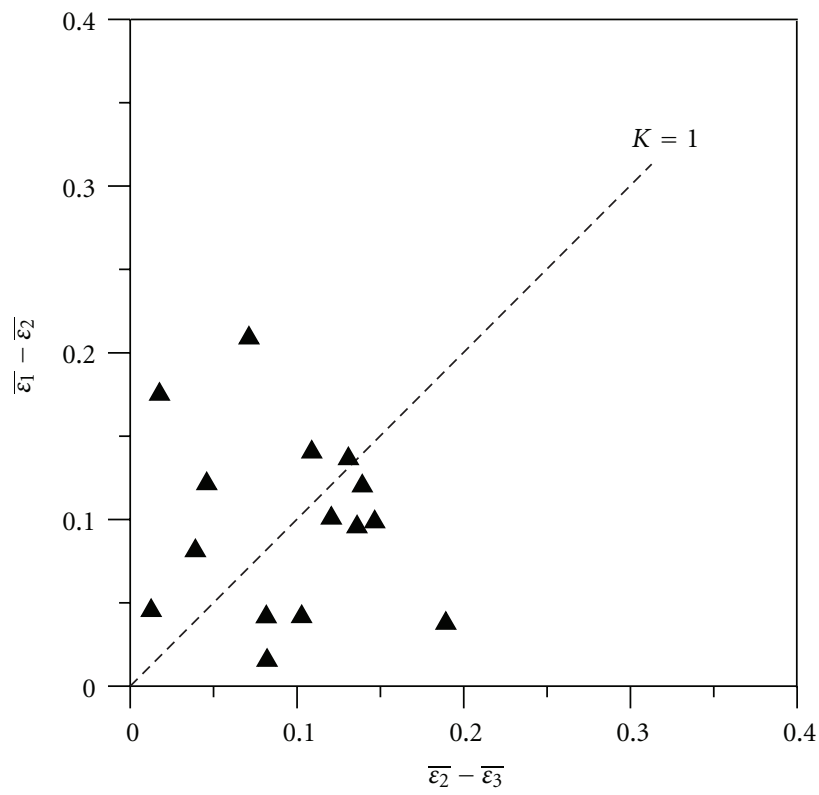

Magmatic belt

(b)

FIGURE 7: RIS-logarithmic Flinn diagrams. The arrowhead directs the evolutionary path of RIS style; $K$-Flinn'S parameter [35], $\left(\varepsilon_{1}-\varepsilon_{2}\right) /\left(\varepsilon_{2}-\right.$ $\left.\varepsilon_{3}\right)$, where $\varepsilon_{1} \ln \left(R_{\max }\right), \varepsilon_{2}=\ln \left(R_{\text {int }}\right), \varepsilon_{3}=\ln \left(R_{\min }\right) ; K=\infty$-uniaxial prolate types; $K=0$-uniaxial oblate types; $K=1$-plane strain types; $1<$ $K<\infty$-constriction types; $0<K<1$-flattening types. 


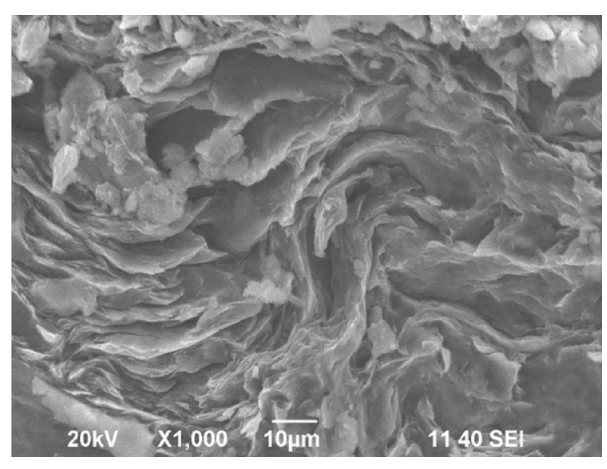

(a)

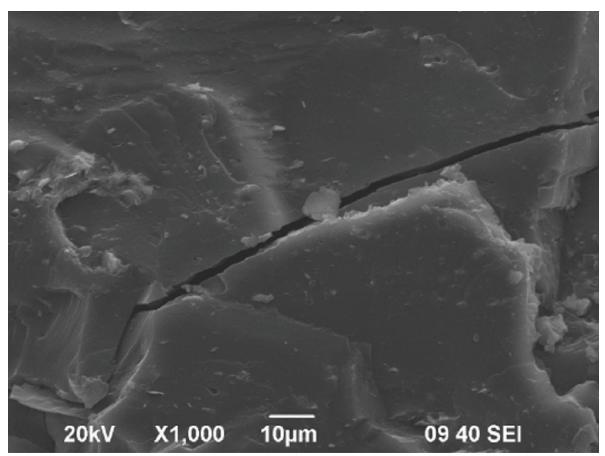

(c)

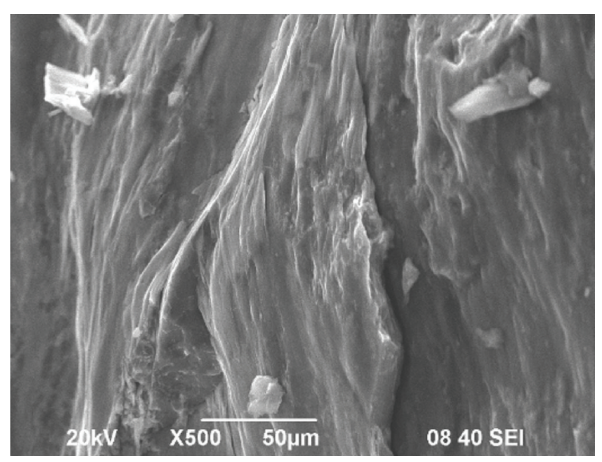

(b)

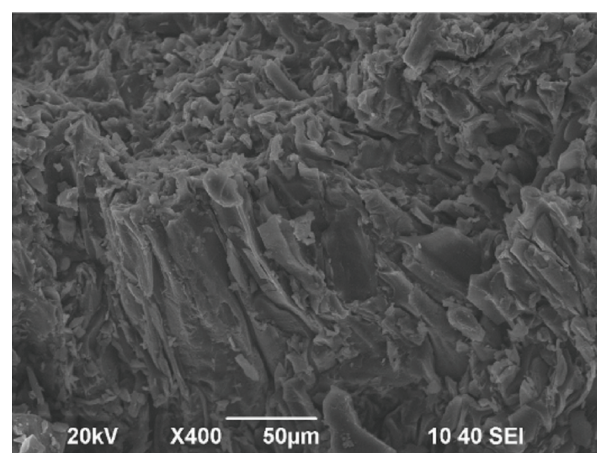

(d)

FIGURE 8: SEM photographs showing different types of deformation. (a) YZM16, strongly folded deformation; (b) LHM05, ductile shear deformation; (c) HZM03, slight deformation, brittle fractures; (d) HZM10, strong deformation, locally folded.

As the suggested route given above, the style of uniaxial negative might take place either in the third stage or in the transition between the first and the second stages. More evidence is needed to constrain the actual process of physical deformation and metamorphism. During coalification, the coal samples collected from three regions likely belong to different evolution stages.

(1) Samples of Region C experienced more effects of tectonic deformation and shearing heat. With significant anisotropy magnitude (higher $B_{w} / R_{\max }$ and $R_{\mathrm{am}}$ value) and biaxial negative style, they have more likely reached into the third stage.

(2) Samples of Region A experienced more effect of burial metamorphism and less influenced by magmatism and tectonic agency. With unimpressive anisotropy magnitude (lower $B_{w} / R_{\max }$ and $R_{\mathrm{am}}$ value) and biaxial negative style, they more likely belong to the transition between the first to the second stage.

(3) Samples of Region B influenced by the Mesozoic magmatism, representing polarized anisotropy magnitude (diversified value of $R_{0}, B_{w} / R_{\max }$ and $R_{\mathrm{am}}$ ). With complicated and various RIS style, they probably belong to the transition between the second and the third stage. Scanning electron microscopic (SEM) photos of coals in the study area indicated that some coal seams have strong deformation (Figure 8). The local stress field was presumably influenced by the complicated volcanic activity such as granite pegmatite and diorite porphyrite during the Yanshanian orogeny [50].

5.3. Implications of RIS-Orientations. As mentioned in Section 1, previous works suggest that minimum reflectance develops incrementally parallel to $\sigma_{1}$ and maximum reflectance develops incrementally parallel to $\sigma_{3}$ during coalification $[1,14]$. These viewpoints were verified by simple shear experiments under high temperature-pressure environment $[28,33,34]$. On this basis, the vitrinite reflectance may provide important information about tectonic stress in each period during the coalification, and the $\sigma_{1}$-direction could be indicated by the minimum reflectance axis.

Eastern North China Craton experienced an important tectonic inversion during Mesozoic. The EW-trending tectonic grain was transformed to NE-NNE-trending and the contractional regime to an extensional regime during Jurassic-Middle Cretaceous [51]. The Huaibei Coalfield lies in the southeastern margin of North China Craton, and influenced by multistage and complicated tectonic events, which could be represented by the triaxial rotation of RIS.

The orientations of RIS axes are respectively projected on the horizontal plane, (Figure 9) and vertical section (Figure 10), and analyzed as follows:

5.3.1. Horizontal Projection. The horizontal projections are based on the stereographic polar method. The radius of base 


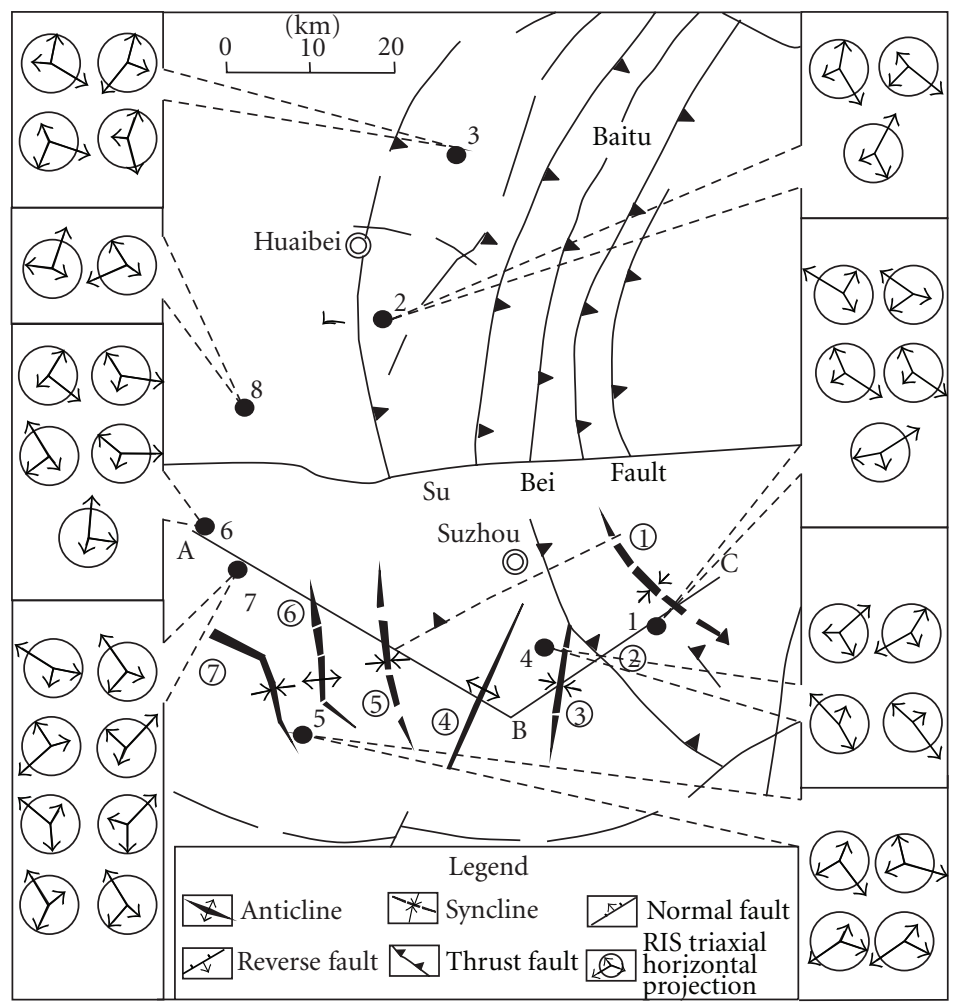

Figure 9: RIS-triaxial horizontal Projection. Coal mine label: 1-Luling mine, 2-Yangzhuang mine, 3-Shitai mine, 4-Taoyuan mine, 5-Xutuan mine, 6-Haizi mine, 7-Linhuan mine, 8-Baishan mine. Structure label: (1) Luling syncline; (2) Xisipo fault; (3) Sunan syncline; (4) Sunan anticline; (5) Nanping syncline; (6) Tongting anticline; (7) Wugou syncline.The radius of base circle represents the value of Rint; long (middle and short) arrows represent $R_{\max }\left(R_{\mathrm{int}}\right.$ and $\left.R_{\min }\right)$.

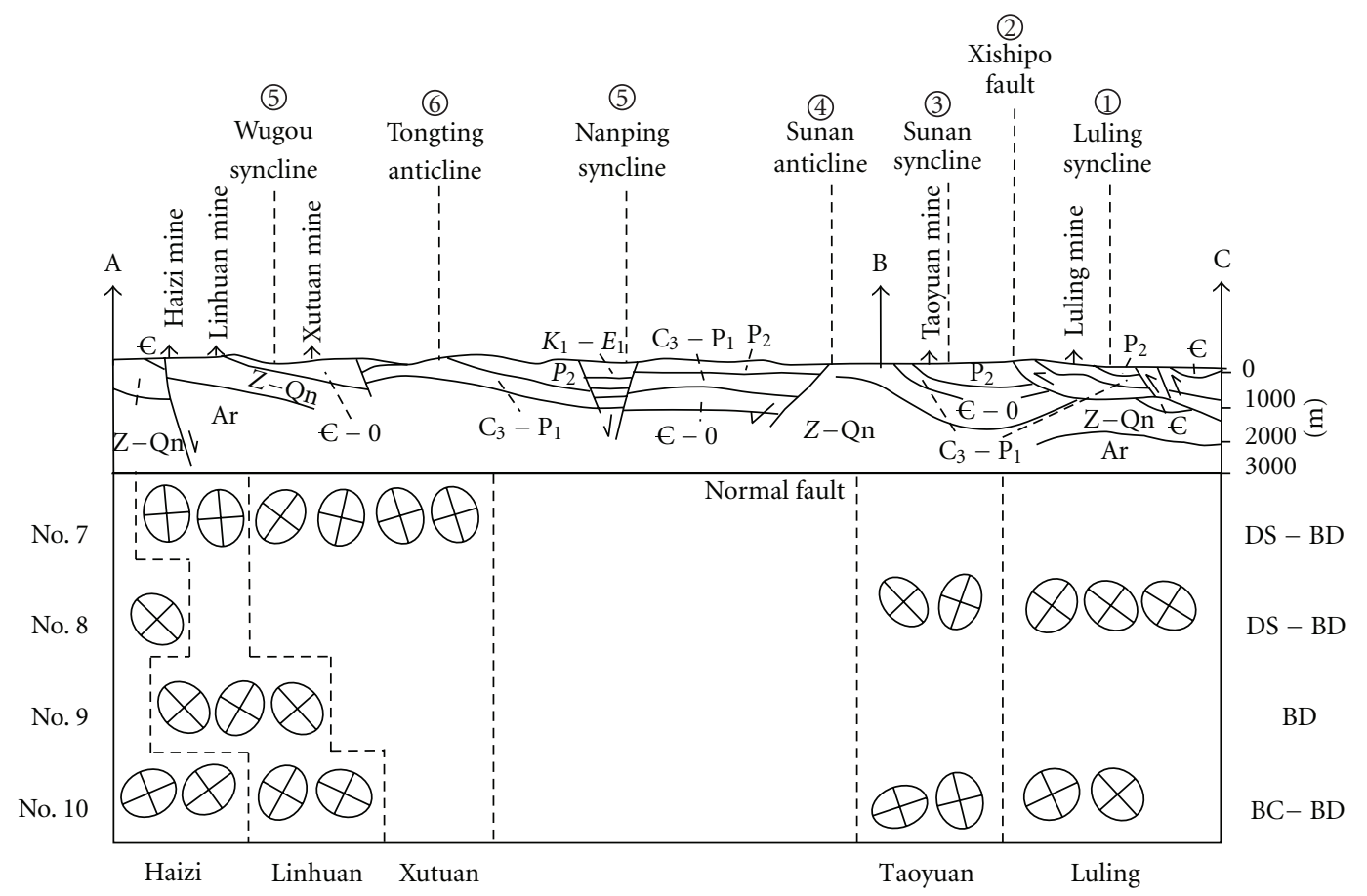

FIGURE 10: RIS-vertical projection. Generally speaking, stronger tectonic agency played the primary role and brought about coal seams to be RIS-orientation basically alike. 
circle represents the value of Rint. Based on the feature that minimum reflectance develops incrementally parallel to $\sigma_{1}$ $[1,14]$, the cumulative effect of multistage tectonism on each sample is indicated by the orientation of $R_{\min }$ axis.

The samples collected from different working faces have different RIS orientation, even though they are in the same coal mine. The samples of Region $C$ are fan-shaped distributing on the thrust arc, and their Rmin axial directions are mainly pointing to the center of the circle such as, from north to south in order, NW-SW or NNW-SSE direction in the Luling mine), NEE-SWW direction in Yangzhuang mine, SSE-NNW or NNE-SSW direction in the Shitai mine. In other words, the $R_{\min }$ axial direction was parallel to the thrust- direction.

The samples of Region A and B are distributing in the front of the thrust arc and a series of NNW-NE-trending folds. Their $R_{\min }$ axial directions are mainly perpendicular to the corresponding fold-hinge as shown in Figure 9. These features suggest that the RIS-orientation in these areas was primarily controlled by the thrust-fold system.

5.3.2. Vertical Projections. The cross-section (A-B-C) is about perpendicular to the hinges of the major folds and its position is shown in Figure 9. The vertical projections on the cross-section are based on RIS-analyses of the samples from five coal mines. Since most of the $R_{\min }$ axial directions are located in the cross-section, the projection provides information on RIS-dip angles.

Samples of the Luling mine belong to Region C, and their RIS orientations were following the direction of thrust. Number 8 coal seam has similar RIS dips as Number 10. However, samples of the Taoyuan mine, Xutuan mine, Linhuan mine and Haizi mine seem to be more influenced by the regional tectonic stress, the distinctions between samples of different coal seam are obvious.

Combining with the deformation type of coal samples (as listed in Table 3), No. 7, No. 8, and No. 9 coal seams are mainly characterized as ductile-type or brittle-ductile-type, with lower $R_{\min }$ axial dip angles. In contrast, N0. 10 coal seam is mainly characterized as brittle-type or brittle-ductile type, and their RIS $R_{\min }$ axial dip angles are higher. The contrastive fact indicates that the coal samples in different deformation types have remarkably different RIS orientation, although they belong to the same structural unit.

\section{Conclusions}

Our results indicate that:

(1) there are obvious relationships between the anisotropic parameters and tectonic stress action. Based on the tectonic situation, the Huaibei Coalfield is divided into three regions. Samples of each region have special RIS-shape and magnitude. Samples of Region $C$ have significant anisotropy magnitude (higher $B_{w} / R_{\max }$ and $R_{\mathrm{am}}$ value) and biaxial negative style. By contrast, samples of the Region A have unimpressive anisotropy magnitude and biaxial negative style. Samples of Region B represent polarized anisotropy magnitude (diversified value of $R_{\mathrm{o}}, B_{w} / R_{\max }$ and $R_{\mathrm{am}}$ ) with complicated and various RIS styles,

(2) orientation of RIS is mainly controlled by regional tectonic stress: either parallel to the direction of thrusting or perpendicular to the hinge of folds. It is likely influenced by deformation mechanisms of coal.

\section{Acknowledgments}

These research results are part of a key project carried out in 2006-2011 and financially supported by The national Natural Science Foundation of China (Grant no. 41030422; 40940014; 40772135) and National Basic Research Program of China (Grant no. 2009CB219601). The authors are grateful to Dai Jiming and Ai Tianjie at China University of Mining and Technology (Beijing) for their assistance in the experiments. Many thanks to Zheng Yadong, Wang Guiliang, Jin Weijun and Liu Qinfu, Liu Dameng, and three reviewers for their help with improving the paper.

\section{References}

[1] I. Stone and A. Cook, "The influence of some tectonic structures upon vitrinite reflectance," The Journal of Geology, vol. 87, pp. 497-508, 1979.

[2] E. Stach, M.-T. Mackowsky, M. Techmuller, G. H. Taylor, D. Chandra, and R. Techmuller, Stach's Textbook of Coal Petrology, 3rd edition, 1982.

[3] J. V. Ross, R. M. Bustin, and J. N. Rouzaud, "Graphitization of high rank coals - the role of shear strain: experimental considerations," Organic Geochemistry, vol. 17, no. 5, pp. 585596, 1991.

[4] R. M. Bustin, J. V. Ross, and J. N. Rouzaud, "Mechanisms of graphite formation from kerogen: experimental evidence," International Journal of Coal Geology, vol. 28, no. 1, pp. 1-36, 1995.

[5] J. Komorek and R. Morga, "Relationship between the maximum and the random reflectance of vitrinite for coal from the Upper Silesian Coal Basin (Poland)," Fuel, vol. 81, no. 7, pp. 969-971, 2002.

[6] S. Pusz, S. Duber, and B. K. Kwiecińska, "The study of textural and structural transformations of carbonized anthracites," Fuel Processing Technology, vol. 77-78, pp. 173-180, 2002.

[7] J. Komorek and R. Morga, "Vitrinite reflectance property change during heating under inert conditions," International Journal of Coal Geology, vol. 54, no. 1-2, pp. 125-136, 2003.

[8] S. Pusz, B. K. Kwiecińska, and S. Duber, "Textural transformation of thermally treated anthracites," International Journal of Coal Geology, vol. 54, no. 1-2, pp. 115-123, 2003.

[9] M. Krzesińska, S. Pusz, and A. Koszorek, "Elastic and optical anisotropy of the single-coal monolithic high-temperature (HT) carbonization products obtained on a laboratory scale," Energy and Fuels, vol. 19, no. 5, pp. 1962-1970, 2005.

[10] D. Y. Cao, X. M. Li, and S. R. Zhang, "Influence of tectonic stress on coalification: stress degradation mechanism and stress polycondensation mechanism," Science in China, Series D, vol. 50, no. 1, pp. 43-54, 2007.

[11] J. P. Jiang, G. Y. Gao, and J. W. Kang, "Tests on vitrinite reflectance of coal and analysis of tectonic stress field," Chinese 
Journal of Geophysics (Acta Geophysica Sinica), vol. 50, no. 1, pp. 138-145, 2007.

[12] J. Komorek and R. Morga, "Evolution of optical properties of vitrinite, sporinite and semifusinite in response to heating under inert conditions," International Journal of Coal Geology, vol. 71, no. 4, pp. 389-404, 2007.

[13] I. Suárez-Ruiz and A. B. García, "Optical parameters as a tool to study the microstructural evolution of carbonized anthracites during high-temperature treatment," Energy and Fuels, vol. 21, no. 5, pp. 2935-2941, 2007.

[14] J. R. Levine and A. Davis, "Optical anisotropy of coals as an indicator of tectonic deformation, Broad Top Coal Field, Pennsylvania ( USA)," Geological Society of America Bulletin, vol. 95, no. 1, pp. 100-108, 1984.

[15] J. R. Levine and A. Davis, "Reflectance anisotropy of Upper Carboniferous coals in the Appalachian foreland basin, Pennsylvania, U.S.A," International Journal of Coal Geology, vol. 13, no. 1-4, pp. 341-373, 1989.

[16] B. Jiang and Y. Qin, "Experimental research on deformation of optical fabric of coal vitrinite reflectance experimental research on deformation of optical fabric of coal vitrinite reflectance," Coal Geology \& Exploration, vol. 25, pp. 11-15, 1997 (Chinese).

[17] J. C. Hower and A. Davis, "Vitrinite reflectance anisotropy as a tectonic fabric element," Geology, vol. 9, pp. 165-168, 1981.

[18] D. Y. Cao, "The vitrinite reflectance anisotropy in the nappe structure in the Huaibei coalfield, Anhni province," Geology Review, vol. 36, pp. 333-340, 1990 (Chinese).

[19] W. Langenberg and W. Kalkreuth, "Reflectance anisotropy and syn-deformational coalification of the Jewel seam in the Cadomin area, Alberta, Canada," International Journal of Coal Geology, vol. 19, no. 1-4, pp. 303-317, 1991.

[20] B. Jiang, F. Y. Xu, Y. Liu, and F. L. Jin, "Vitrinite optical fabric and stress-strain analysis of northern margin of Chaidamu Basin," Journal of China University of Mining \& Technology, vol. 31, pp. 561-564, 2002.

[21] J. Jones and S. Creaney, "Optical character of thermally metamorphosed coals of northern England," Journal of Microscopy, vol. 109, pp. 105-118, 1977.

[22] G. K. Khorasani, D. G. Murchison, and A. C. Raymond, "Molecular disordering in natural cokes approaching dyke and sill contacts," Fuel, vol. 69, no. 8, pp. 1037-1046, 1990.

[23] W. E. Kilby, "Recognition of vitrinite with non-uniaxial negative reflectance characteristics," International Journal of Coal Geology, vol. 9, no. 3, pp. 267-285, 1988.

[24] W. E. Kilby, "Vitrinite reflectance measurement-some technique enhancements and relationships," International Journal of Coal Geology, vol. 19, no. 1-4, pp. 201-218, 1991.

[25] J. C. Hower, R. F. Rathbone, G. D. Wild, and A. Davis, "Observations on the use of vitrinite maximum reflectance versus vitrinite random reflectance for high volatile bituminous coals," Journal of Coal Quality, vol. 13, pp. 71-76, 1994.

[26] K. R. Wilks, M. Mastalerz, R. M. Bustin, and J. V. Ross, “The role of shear strain in the graphitization of a high-volatile bituminous and an anthracitic coal," International Journal of Coal Geology, vol. 22, no. 3-4, pp. 247-277, 1993.

[27] D. W. Houseknecht and C. M. B. Weesner, "Rotational reflectance of dispersed vitrinite from the Arkoma basin," Organic Geochemistry, vol. 26, no. 3-4, pp. 191-206, 1997.

[28] J. V. Ross and R. M. Bustin, "Vitrinite anisotropy resulting from simple shear experiments at high temperature and high confining pressure," International Journal of Coal Geology, vol. 33, no. 2, pp. 153-168, 1997.
[29] S. Duber and J. N. Rouzaud, "Calculation of relectance values for two models of texture of carbon materials," International Journal of Coal Geology, vol. 38, no. 3-4, pp. 333-348, 1999.

[30] S. Duber, S. Pusz, B. K. Kwiecińska, and J. N. Rouzaud, "On the optically biaxial character and heterogeneity of anthracites," International Journal of Coal Geology, vol. 44, no. 3-4, pp. 227250, 2000.

[31] A. C. Cook, D. G. Murchison, and E. Scott, "Optically biaxial anthracitic vitrinites," Fuel, vol. 51, no. 3, pp. 180-184, 1972.

[32] F. Ting, "Uniaxial and biaxial vitrinite reflectance models and their relationship to paleotectonics," in Organic Maturation Studies and Fossil Fuel Exploration, J. Brooks, Ed., pp. 379-392, Academic Press, London, UK, 1981.

[33] R. M. Bustin, J. V. Ross, and I. Moffat, "Vitrinite anisotropy under differential stress and high confining pressure and temperature: preliminary observations," International Journal of Coal Geology, vol. 6, no. 4, pp. 343-351, 1986.

[34] B. Jiang, F. Jin, Q. Zhou, and W. Wang, "Experimental research on deformation of optical fabric of coal vitrinite reflectance," Coal Geology \& Exploration, vol. 25, pp. 11-15, 1997 (Chinese).

[35] J. G. Ramsay, Folding and Fracturing of Rocks, Mc Graw-Hill, New York, NY, USA, 1967.

[36] Y. D. Wu, Y. W. Ju, Q. L. Hou, S. Hu, S. Q. Ni, and J. J. Fan, "Characteristics of tectono-thermal modeling and restriction on coalbed-gas generation in Sulin mining area, Huaibei coalfield," Progress in Natural Science, vol. 19, pp. 1134-1141, 2009 (Chinese).

[37] W. Guiliang, J. Bo, C. Daiyong, Z. Hai, and J. Weijun, "On the Xuzhou-Suzhou arcuate duplex-imbricate fan thrust system," Acta Geologica Sinica, vol. 72, no. 3, pp. 235-236, 1998.

[38] Y. W. Ju, Q. L. Hou, B. Jiang, G. L. Wang, and A. M. Fang, “Tectonic coals: structure and physical properties of reservoirs," in Proceedings of the Proceedings of the 6th International Workshop on CBM/CMM in China, Beijing, China, 2006.

[39] G. Zhu, C. Song, D. Wang, G. Liu, and J. Xu, "Studies on ${ }^{40} \mathrm{Ar} /$ ${ }^{39}$ Ar thermochronology of strike-slip time of the Tan-Lu fault zone and their tectonic implications," Science in China, Series D, vol. 44, no. 11, pp. 1002-1009, 2001.

[40] G. Zhu, Y. Wang, G. Liu, M. Niu, C. Xie, and C. Li, " ${ }^{40} \mathrm{Ar} /$ ${ }^{39}$ Ar dating of strike-slip motion on the Tan-Lu fault zone, East China," Journal of Structural Geology, vol. 27, no. 8, pp. 13791398, 2005.

[41] G. Zhu, C. L. Xie, Y. S. Wang, M. L. Niu, and G. S. Liu, "Characteristics of the Tan-Lu high-pressure strike-slip ductile shear zone and its ${ }^{40} \mathrm{Ar} /{ }^{39} \mathrm{Ar}$ dating," Acta Petrologica Sinica, vol. 21, no. 6, pp. 1687-1702, 2005.

[42] A. Yin and S. Nie, "An indentation model for the north and south China collision and development of the Tan-Lu and Honam fault systems, Eastern Asia," Tectonics, vol. 12, pp. 810813, 1993.

[43] G. Zhu, Y. S. Wang, N. M. Lan, G. S. Liu, and C. L. Xie, "Synorogenic movement of the Tan-Lu fault zone," Earth Science Frontiers, vol. 11, pp. 169-182, 2004 (Chinese).

[44] D. Liu, Y. Yao, D. Tang, S. Tang, Y. Che, and W. Huang, "Coal reservoir characteristics and coalbed methane resource assessment in Huainan and Huaibei coalfields, Southern North China," International Journal of Coal Geology, vol. 79, no. 3, pp. 97-112, 2009.

[45] D. Flinn, "On folding during three-dimensional progressive deformation," Quarterly Journal of the Geological Society, vol. 118, pp. 385-428, 1962. 
[46] C. Barker and M. Pawlewicz, "The correlation of vitrinite reflectance with maximum temperature in humic organic matter," Lecture Notes in Earth Science, vol. 5, pp. 79-81, 1986.

[47] F. Goodarzi and D. G. Murchison, "Optical properties of carbonized vitrinites," Fuel, vol. 51, no. 4, pp. 322-328, 1972.

[48] D. G. Murchison, "Petrographic aspects of coal structure: reactivity of macerals in laboratory and natural environments," Fuel, vol. 70, no. 3, pp. 296-315, 1991.

[49] S. Duber, J. N. Rouzaud, C. Clinard, and S. Pusz, "Microporosity and optical properties of some activated chars," Fuel Processing Technology, vol. 77-78, pp. 221-227, 2002.

[50] G. L. Wang, B. Jiang, D. Y. Cao, H. Zou, and W. J. Jin, "On the Xuzhou-Suzhou arcuate duplex-imbricate fan thrust system.," Acta Geologica Sinica (in Chinese with English summary), vol. 72, pp. 228-236, 1998.

[51] M. Zhai, R. Zhu, J. Liu et al., "Time range of Mesozoic tectonic regime inversion in eastern North China Block," Science in China, Series D, vol. 47, no. 2, pp. 151-159, 2004. 

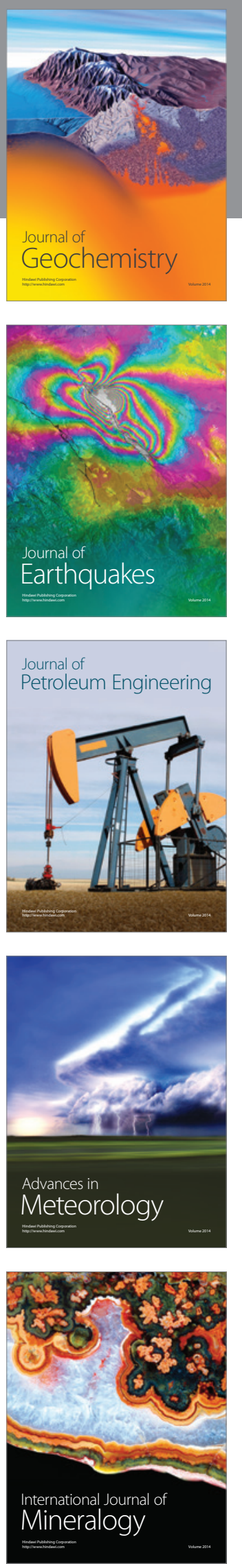
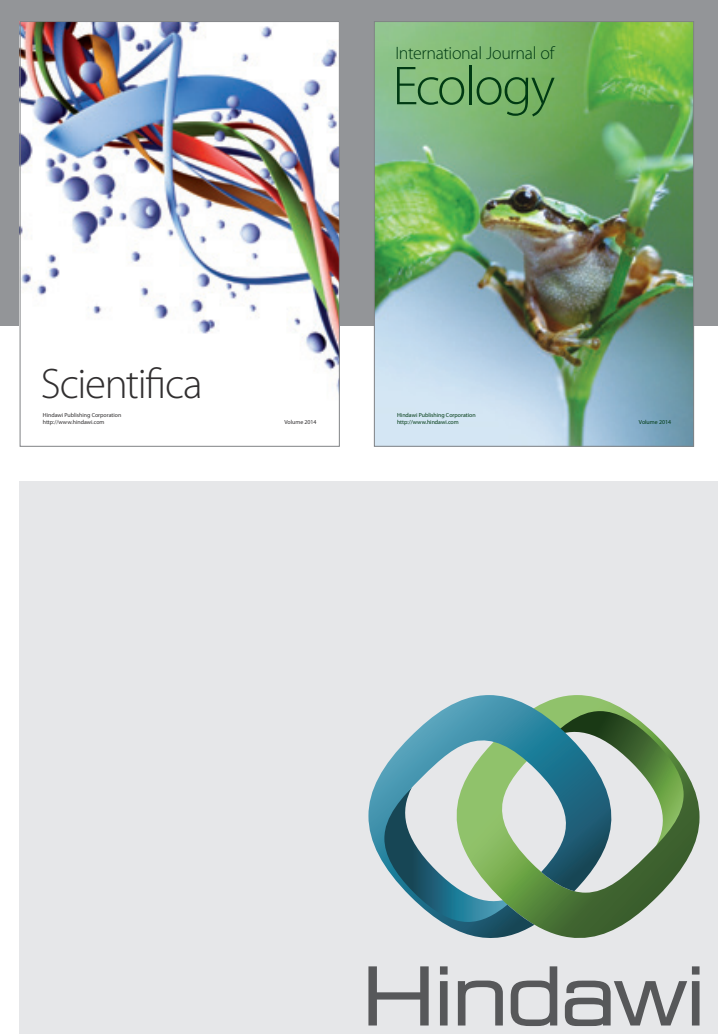

Submit your manuscripts at http://www.hindawi.com
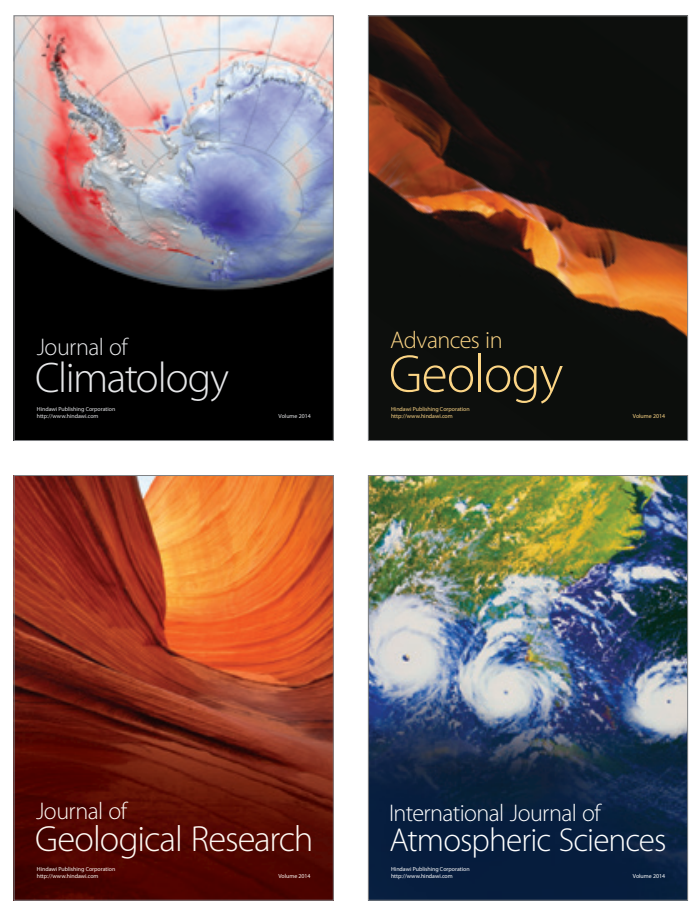
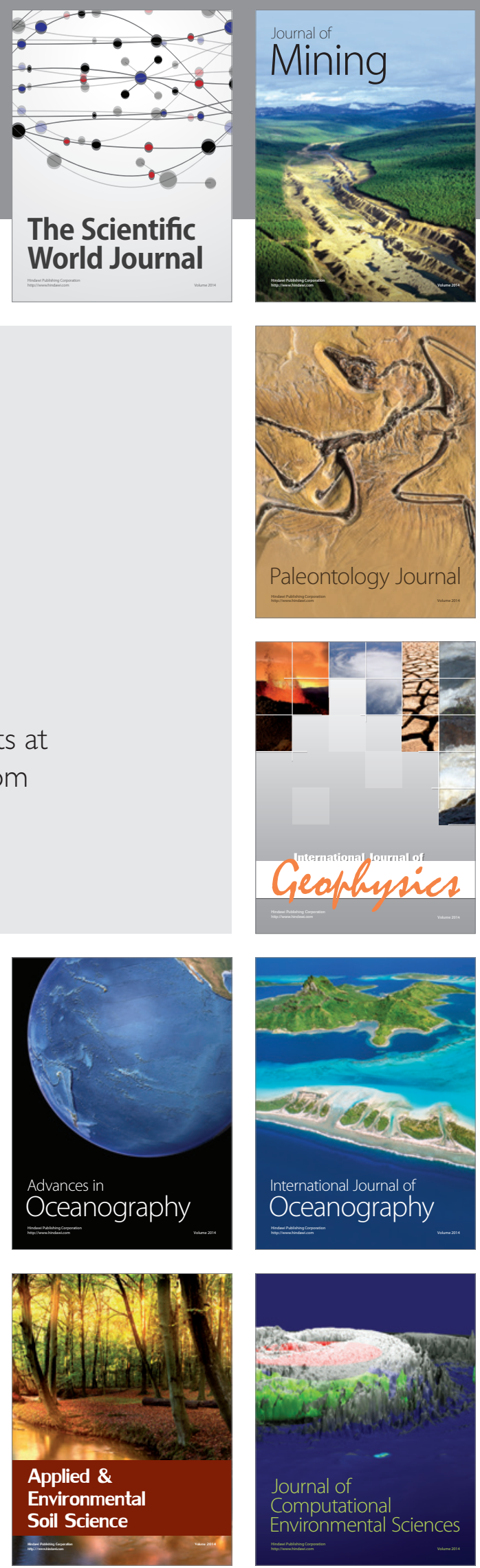